\title{
LA TRANSFORMACIÓN DEL CONCEPTO CONSTITUCIONAL DE familia. Alcances DE UNA PROBLEMÁTICA TEÓRICA
}

\section{TRANSFORMATION OF A CONSTITUTIONAL Concept. The SCOPE OF A Theoretical Problem}

\section{A TRANSFORMAÇÃO DO CONCEITO COnstitucional. Alcances de uma PROBLEMÁTICA TEÓRICA}

\author{
JOSÉ ALEJANDRO MACHADO-JIMÉNEZ*
}
* Profesor de la Facultad de Derecho, Universidad de Cartagena (Colombia). Abo- gado y filósofo, licenciado y doctor en Derecho Canónico por la Pontificia Univer- sidad de la Santa Cruz (Roma). alemach94@gmail.com

RECIBIDO: 1 DE MARZO DE 2013. ENVÍO A PARES: 27 DE MAYO DE 2013. APROBAdO POR PARES: 23 DE JULIO DE 2013. ACEPTADO: 4 DE SEPTIEMBRE DE 2013.

DOI: $10.5294 / D I K A .2014 .23 .1 .5$

PARA CITAR ESTE ARTículo / TO REFERENCE THIS ARTICLE / PARA CITAR ESTE ARTIGO MACHADO-JIMÉNEZ JOSÉ ALEJANDRO, LA TRANSFORMACIÓN DEL CONCEPTO CONSTITUCIONAL de familia. AlCANCES de una problemática teórica, en DiKaion, 23-1 (2014), 


\section{RESUMEN}

El presente artículo mostrará, a partir de un análisis teórico, la transformación que pretenden imponer algunas decisiones hito de la Corte Constitucional colombiana al reconocimiento de la familia en la Constitución Política de 1991, artículo 42, por la vía de la argumentación formalística empleada para tutelar en abstracto posibles controversias patrimoniales y afectivas de las parejas que practican la homosexualidad. Las perspectivas que ofrecen las reglas de la Corte en sus argumentaciones y las consecuencias que pudieran llegar a tener frente a la sistemática del derecho de familia colombiano actualmente vigente, se tratarán en una segunda parte del trabajo reservada para una próxima entrega.

\section{PALABRAS CLAVE:}

Parejas homosexuales, familia de fundación heterosexual, argumentación formalística. 


\begin{abstract}
Based on a theoretical analysis, this article shows how several landmark decisions by the Constitutional Court of Colombia represent an attempt to change the way the family is recognized in Article 42 of the country's 1991 Constitution, by means of a formalistic argument used to protect, in the abstract, possible financial and emotional disputes among homosexual couples. The perspectives offered by the rules of the Court in its arguments and the consequences they would have for the system of Colombian family law currently in force, will be discussed in a second part of this work reserved for future delivery.
\end{abstract}

\title{
KEY WORDS:
}

Homosexual couples, family founded on heterosexual unions, formalistic argument. 


\section{RESUMO}

O presente artigo mostra, a partir de uma análise teórica, a transformação que algumas decisões da Corte Constitucional colombiana pretendem impor ao reconhecimento da família na Constituição Política de 1991, artigo 42, pela via da argumentação formalística empregada para tutelar em abstrato possiveis controvérsias patrimoniais e afetivas dos casais que praticam a homossexualidade. As perspectivas que as regras da Corte oferecem em suas argumentações e as consequências que podem chegar a ter ante a sistemática do direito de família colombiano atualmente vigente serão tratadas numa segunda parte do trabalho, reservada para uma próxima entrega.

\section{PALAVRAS-CHAVE:}

Casais homoafetivos, família de fundação heterossexual, argumentação formalística. 
Sumario: Introducción; 1. Ámbitos argumentativos contenidos en las decisiones de la Corte; 1.1.

Primeros pasos; 1.2. Introducción de la adopción por homosexuales; 1.3. El Regreso al MODELO DEL CONTRATO MATRIMONIAL: HACIA LA C-577 DE $2011 ; 1.4$. REPETICIONES AL EXAMEN DE CONStitucionalidad; 1.5. La génesis del argumento formalista; 1.6. La Ratio de LA C-577 de 201 1: las apreciaciones globales; 2. Conclusión; Bibliografía.

\section{INTRODUCCIÓN}

La argumentación con la que un juez toma una decisión que compromete interpretativamente a la vida de la Constitución Política de una nación, no solo está provista de una subsunción lógica de los componentes gramaticales, teleológicos de las normas y del sistema jurídico con las hipótesis o los hechos que examina. Cada argumento compromete al juez u órgano judicial en su misión de mostrar a su nación la manera de comprender mejor la realidad sobre la que se pronuncia. Con su prudencia el juez da vida a las exigencias de justicia de las personas y la comunidad, y la interpretación que haga de la norma es la herramienta que precisa la delicada misión.

La Corte Constitucional colombiana, desde hace más de diez años, viene presentando en sus fallos argumentos para entender mejor los alcances del artículo 42 de la Constitución Política, que trata sobre la familia, especialmente sobre los vínculos que permiten un reconocimiento y protección especial de parte del Estado. Sin embargo, a pesar de evidenciar una uniformidad hermenéutica hasta el año 2007, la Corte rompe con la misma uniformidad, y comienza a dar alcances distintos a los conceptos que el artículo 42 de la Constitución presenta respecto a la fundación nuclear de la familia, dando el paso a que las prácticas homosexuales de una pareja se asimilen completamente, en lo que les pueda corresponder, a las consecuencias jurídicas que tienen las uniones heterosexuales que consiguen fundar un vinculo familiar por el compromiso responsable y ante las dinámicas de existencia del amor que se manifiestan, incluyendo la apertura a una comunidad doméstica de crianza y solidaridad. La Corte asume un nuevo protagonismo bajo el supuesto de que, siendo guardiana de la Constitución, y en su deber de interpretarla, muestra cómo debe haber una especial protección por parte del Estado a la decisión soberana y responsable de conformar una familia por quienes practiquen la homosexualidad.

Pero los cambios conceptuales no parecen surgir de una propuesta de la Corte frente a la familia que responda protagónicamente a soluciones por las necesidades que surgen de las desarmonías o disfuncionalidades, y que generalizan los conflictos en algunas de las familias colombianas. Los cambios conceptuales se presentan ante una necesidad que, considera la Corte desde el año 2007, nunca se había puesto en consideración, y que consiste en las prácticas homosexuales de las personas que, siendo del mismo sexo conviven como pareja, y requieren especial protección del Estado, por causa de la existencia de unos eventuales vínculos de solidaridad y por un sentimiento de injusta discriminación generalizado en la sociedad colombiana, según lo alegan quienes se presentan ante la Corte como defensores sociales de la homosexualidad. 
Para precisar cómo se produce un cambio conceptual en la Corte Constitucional, de lo que juridicamente se pueda llegar entender como familia fundada en la heterosexualidad, se requiere un análisis que, hasta el momento, en la argumentación de la Corte presentaría dos caminos: el primero, el de hacer patente las contingencias que en el derecho de familia genera la extensión de un régimen familiar a las dinámicas vitales de las parejas homosexuales y, el segundo, la necesidad de comprender el ámbito de la argumentación que da origen a la regla presentada por la Corte Constitucional relativa a que a las parejas que comparten prácticas homosexuales se les apliquen las normas legales que el derecho positivo vigente en Colombia dispone para las formas familiares de fundación heterosexual.

Como quiera que en el derecho colombiano vigente se impone la integración de los ordenamientos jurídicos: el del derecho civil y el del derecho constitucional, estableciendo entre ellos de manera abstracta una jerarquía (la Constitución es "norma de normas"), se comenzará por la segunda vía anunciada y se terminará con la primera. La paradoja será que la primera vía se presentará en una segunda entrega, y comprende las tensiones que subsisten en el derecho colombiano si se mantiene el cambio conceptual de la Corte hasta sus consecuencias. La secuencia propuesta permite facilitar la comprensión de la problemática a quienes les interese estudiar los fenómenos jurídicos desde las formalizaciones abstractas de argumentos plausibles, y también a quienes pueden llegar a necesitar comprender, desde una perspectiva diacrónica, las lineas argumentativas de la Corte Constitucional colombiana, en un tópico como es el de la protección, que dice la Corte pretende ofrecer, a las parejas que practican la homosexualidad incluyéndolas en los mismos supuestos normativos de la pareja heterosexual que dan origen a una unidad y estructura de relaciones familiares.

\section{1. Ámbitos argumentativos contenidos en las DECISIONES DE LA CORTE}

\subsection{Primeros pasos}

La Corte Constitucional colombiana, mediante sentencia C-075 de 2007, encontró, en un examen de exequibilidad de las disposiciones legales relativas a la formación de las uniones entre compañeros y las respectivas sociedades patrimoniales, que las parejas homosexuales carecian de un régimen de protección patrimonial, así como lo tienen las parejas heterosexuales. Surgió para la Corte un nuevo supuesto: en las prácticas homosexuales de una pareja convergen vínculos de solidaridad económica, y, por tanto, ordenó que el mismo régimen patrimonial se extendiera a esas formas de pareja. No era la primera vez que la Corte abordaba un estudio sobre este tema, el análisis ya lo había presentado la Corte en una sentencia anterior del año 1996 (C-098 de 1996), por las mismas razones y contra el mismo dispositivo, los artículos 1 y 2 de la Ley 54 (la reforma de la Ley 979 de 2005 no reguló los temas presentados en los cargos sino otros de relevancia probatoria) ${ }^{1}$.

1 Puede verificarse el informe de Conciliación al Proyecto de Ley 29 de 2003, Senado; 148 de 2003, Cámara, que concluye el debate legislativo que da origen a la Ley 979, en http:servoaspr.imprenta.gov. 
En efecto, la sentencia C-098 declaró que las normas demandadas se ajustaban a la Constitución. Sin embargo la Corte, al admitir la demanda, formuló un nuevo análisis para argumentar la decisión que tomó en la C-075 de 2007, también sobre los artículos 1 y 2 (que incluye la modificación que introdujo la Ley 979 solo al art. 2). La cuestión en la C-075 se abordó de la siguiente manera:

1. En la sentencia C-098 de 1996, no hubo cosa juzgada constitucional respecto al problema de desprotección de las parejas. Entonces sería necesario que el nuevo examen fuera por "un supuesto distinto", y en el entendido que la C-098 se refirió solo a "la supuesta violación de los artículos constitucionales señalados en la demanda (art. 1, principio de pluralismo; art. 13, Principio de igualdad real y efectiva; art. 16, Libre desarrollo de la personalidad; art. 18, Libertad de conciencia, y art. 21, derecho a la honra)". La C-075 dice que la Corte, en la sentencia C-098 de 1996: "dejó abierta la posibilidad de un nuevo examen de constitucionalidad, si se establecía que de las normas acusadas se desprendía un privilegio ilegitimo, o se advirtiese en ellas un propósito de lesionar a los homosexuales o se llegase a la conclusión que de su aplicación pudiera esperarse un impacto negativo en contra de estos". Para contestarle a los demandantes dice la C-075 que la cosa juzgada implícita se da cuando la sentencia que haya examinado la normativa

"restringe en la parte motiva el alcance de la cosa juzgada, aunque en la parte resolutiva no se indique dicha limitación" y que "no se requiere que la Corte confronte las normas demandadas con todas y cada una de las normas superiores para que se entienda que, salvo manifestación en contrario, su pronunciamiento tiene el alcance de cosa juzgada absoluta”.

Paradójicamente, la Corte no da la razón a los demandantes para que por ese motivo digan que no operó la cosa juzgada relativa implícita en la C-068. Sin embargo, para la C-075 el régimen patrimonial "cuya constitucionalidad se pone de nuevo en entredicho” al ser modificado por la Ley 979 de 2005 pues esta nueva ley "incorporó ingredientes nuevos de enorme significación, en cuanto que en ella, si bien a través de instrumentos que, en principio, tienen alcance meramente probatorio, se permite que las parejas, cumplidos ciertos supuestos, accedan de manera voluntaria a un régimen de regulación de sus relaciones patrimoniales".

¿Cuáles podrían ser los ingredientes nuevos de enorme significado? Es necesario considerar que las parejas antes de la expedición de la Ley 979 de 2005, sí podían acceder de manera voluntaria a un régimen como el contemplado en

co. Fecha de consulta: 24 de agosto de 2014. Respecto del análisis que hizo la Corte en la C-098 de 1996 es interesante observar la puesta en escena de las discusiones entre los magistrados que presenta el profesor Gabriel Mora en su obra Justicia constitucional y arbitrariedad de los jueces (2009), pues muestra cómo en algunas expresiones presentes en la parte motiva de la sentencia parece que la Corte se propusiera reformar la propia noción de familia recogida en el texto constitucional, a pesar de que desde el punto de vista lingüístico no exista duda. 
la reforma, también cumpliendo como lo dice la Corte "ciertos supuestos"2. La modificación, como se podrá percibir al comparar los dos textos legales (Ley 54 y Ley 979), se da especialmente en la declaración de existencia de la misma y en las posibilidades de que las conformen personas que tengan impedimento matrimonial de vínculo anterior: ya hicimos el análisis de cuáles impedimentos se mantienen como situaciones que no pueden pretenderse con los mismos efectos de la sociedad patrimonial. Pero, para la Corte, la reforma introducida por la ley 979, representa una "ausencia de reconocimiento de un régimen patrimonial para las uniones homosexuales, implica dejarlas en situación de desprotección frente a normas imperativas del derecho civil y comporta un trato discriminatorio frente a las parejas heterosexuales, cuya situación patrimonial sí ha sido objeto de regulación". Y concluye así la C-075: "De este modo el conjunto normativo sobre el que hoy se propone el ejercicio del control de constitucionalidad es formal y materialmente distinto de aquel que fue objeto de consideración por la Corte en el año de 1996, y no ha operado en relación con el mismo el fenómeno de la cosa juzgada constitucional".

Sin embargo, la reforma contenida en la Ley 979 no introdujo cambios a los elementos fácticos de la heterosexualidad que definen la conformación de las uniones maritales entre compañeros, tal reforma solo añadió facilidades probatorias para el reconocimiento jurídico de los vínculos familiares de las uniones de hecho ${ }^{3}$. Entonces, ¿qué relación tiene la prueba de existencia o forma de declaración de existencia de la unión marital de hecho, con los elementos fácticos de heterosexualidad que la ley define como conformativos de las uniones maritales?, ¿el cambio que introduce la Ley 979 es relevante para los cargos propuestos en la demanda que motivó la sentencia C-075, como sería abordar la cuestión de la homosexualidad?, ¿puede la Corte Constitucional hacer un examen de constitucionalidad con elementos de análisis que no hayan propuesto los demandantes como el del cambio que introduce la Ley 979, para argumentar de manera suficiente que no existió cosa juzgada o que la demanda es bajo "un supuesto distinto"?, ¿puede la Corte decir que la demanda es bajo un "supuesto distinto", cuando los mismos demandantes argumentan que la Corte debe estudiar de nuevo las normas demandadas porque hay cosa juzgada relativa implícita, aún siendo la misma Corte la que dice en la parte motiva de la sentencia que esta forma de cosa juzgada no opera en este caso, pero que ella sí puede "bajo un supuesto distinto", impostar lo que por sí misma deduce como problema jurídico?

2. Aquí se cita el "supuesto distinto", que no es analizado en la argumentación, lógicamente, sino que es tomado como conclusión en la C-075:

2 Por la declaración notarial de mutuo acuerdo, la ley le daba plenos efectos a la declaración de la existencia de esa sociedad patrimonial como claramente lo afirma la Corte en una sentencia, la C-239 de 1994, donde se examina precisamente este mismo supuesto de la prueba de existencia y la manera de hacer valer los derechos de las parejas.

3 Cfr. Informe de Conciliación al Proyecto de Ley 29 de 2003, Senado; 148 de 2003, Cámara, cit. supra. 
"Los homosexuales que cohabitan se encuentran desprotegidos patrimonialmente, porque al terminarse la cohabitación no tienen herramientas jurídicas para reclamar de su pareja la parte que les corresponde en el capital que conformaron durante el tiempo de convivencia, desprotección que es también evidente en el evento de muerte de uno de los integrantes de la pareja, caso en el cual, por virtud de las normas imperativas del derecho de sucesiones, el integrante supérstite podría ser excluido de la titularidad de los bienes que conformaban ese patrimonio, por el derecho de los herederos del causante".

La sentencia llegó a esta conclusión sin considerar o analizar las explicaciones que ofrecieron algunos de los intervinientes, como es el caso del profesor Medina PABón, quien mostró cómo en el derecho privado existen fórmulas equitativas para que los integrantes de cualquier pareja accedan -también en el evento de la muerte- a parte de la titularidad de los bienes que adquirieron junto con su conviviente, sin que necesariamente tal relación se caracterice o regule en la ley demandada, por ejemplo, la actio in rem verso y la acción de enriquecimiento sin causa ${ }^{4}$.

3. Consecuente con la anterior conclusión, considera la Corte que hay una forma de desprotección que reconduce a una forma de discriminación porque la ley no puede hacer especiales consideraciones respecto a las preferencias sexuales de las personas en razón de cualquier distingo, ya que se encuentra proscrito por el ordenamiento jurídico colombiano. En efecto, ilustra la Corte cómo en el ordenamiento jurídico, al imperar los principios de pluralismo, principio de igualdad real y efectiva, libre desarrollo de la personalidad, libertad de conciencia, derecho a la honra, se prohíbe cualquier forma de discriminación por razón de las prácticas o preferencias sexuales. La Corte, en la sentencia C-068, había analizado las mismas disposiciones demandadas también bajo el cargo de la discriminación, concluyendo que tal discriminación no se producía. Pero ahora dice que sí. Las disposiciones demandadas respecto de las parejas homosexuales lesionarían su autonomía y capacidad de autodeterminación dado que: "impedir que su decisión de conformar un proyecto de vida en común produzca efectos jurídico patrimoniales, significa que, dado un régimen imperativo del derecho civil, quedan en una situación de desprotección que no están en capacidad de afrontar". Al parecer, para justificar ese cambio en la jurisprudencia - sin decir que se producía un cambio pues tendría que justificar suficientemente el porqué del mismo - la Corte no examina un criterio que a mi parecer resultaría necesario para la motivación de la sentencia y es el de si es cierto que en el derecho civil subsiste una desprotección para estas parejas. A pesar de algunos elementos de juicio que ofrecieron algunos de los intervinientes en los que le mostraban a la Corte que tal situación no ocurría, la Corte dio por totalmente presentada la desprotección, incluso argumentando que el derecho civil impone un régimen imperativo, pero sin decirnos cómo. Y es que no abordó tampoco el tema que le hubiera permitido motivar

4 Juan Enrique Medina Pabón, Derecho civil: derecho de familia, 3 ed., Bogotá, Universidad del Rosario, 2011, pp. 352-357. 
el cambio jurisprudencial que introdujo, y con más calado argumentativo, de si el derecho civil impone regimenes discriminatorios cuando uno de los principios jurídicos que lo fundan es la autodeterminación de la propia voluntad precisamente con el propósito de asumir la responsabilidad por las propias decisiones, de manera que siempre está presente el principio de nemo auditur alegans propiam culpam. Base también del derecho de la responsabilidad civil. Ese mismo camino argumentativo que la Corte tomó nos llevaría también a pensar que en otras relaciones del derecho privado (aplicable, por ejemplo, en las comerciales) de las que existen normas legales que se aplican por razón del tipo y contenido de relación en que las personas consienten o suscitan, si tales situaciones a las que ellas mismas hayan en su momento decidido obligarse, y por el camino piensen que cumplirlas les obstaculiza un cambio que en el terreno de su vida se les ocurra hacer, entonces podrán solicitar "en derecho" que no se les aplique por cuanto es un régimen que resulta incompatible con el ejercicio del libre desarrollo de la personalidad. Y concluye así la Corte, de entrada, que las disposiciones demandadas de la Ley 54 someten a las parejas homosexuales "a un régimen que resulta incompatible con una opción vital a la que han accedido en ejercicio de su derecho al libre desarrollo de la personalidad". Y añade seguidamente que la legislación ha sido "indiferente ante los eventos de desprotección a los que puede dar lugar tratándose de parejas homosexuales". En el examen del cargo que hace la Corte se concluye, pues, con dos situaciones: 1) la Ley 54 impone un régimen incompatible con opciones vitales de los homosexuales; 2) la Ley 54 es indiferente ante los eventos de desprotección a las parejas homosexuales. ¿Si la ley impone un régimen incompatible, es por tanto indiferente? Parece haber una contradicción en el argumento que le sirvió a la Corte para su análisis.

4. En algunas de las intervenciones se pusieron presentes otras situaciones que muestran cómo, a la luz de lo dispuesto en el artículo 42 de la Constitución Política, tiene vigencia la Ley 54. Como el constituyente, cuando planteó las familias de origen no matrimonial, tenía presente el dispositivo de la Ley 54 en el que la heterosexualidad se considera como un elemento conformativo del inicio de la vida de una pareja que funda la familia, y en efecto y razón de las dinámicas que tiene. Sin embargo, la Corte, en la C-075, no ofreció algún argumento en el que se abordasen las situaciones presentadas en las mencionadas intervenciones. Por el contrario, la aclaración de voto que presentó el magistrado Jaime Araújo Rentería sỉ abordó algunas de estas cuestiones, pero solo volverán a aparecer después, cuando el mismo grupo interesado de actores demande el artículo 113 del Código Civil, en el que se define el matrimonio bajo el supuesto de la heterosexualidad, y que da paso a la sentencia C-577 de 2011.

Así, mediante la C-075 de carácter interpretativo, la Corte en ese fallo encuentra necesario que el régimen patrimonial establecido en la Ley 54 de 1990, junto con las disposiciones relativas a la forma de prueba, se apliquen a las personas que en su vida de pareja practiquen la homosexualidad. Y a partir de esa sentencia es que una pareja o "expareja" podría solicitar que en caso de fallecimiento o se- 
paración se declare la existencia de una sociedad patrimonial y se liquide, o que ambos integrantes declaren su existencia para en ese momento, o después, liquidarla. Es necesario aclarar que la Corte no hace en esta sentencia un análisis de si el vínculo afectivo de la homosexualidad presente en las prácticas de una pareja que la profesa dentro de sí da por sí misma origen a una familia. Solo de manera suelta, es decir, sin ninguna hilación argumentativa, se encuentra expresado lo siguiente, y antes del decisum:

"A la luz de los anteriores criterios y sin desconocer el ámbito de configuración del legislador para la adopción, en proceso democrático y participativo, de las modalidades de protección que resulten más adecuadas para los requerimientos de los distintos grupos sociales, encuentra la Corte que es contrario a la Constitución que se prevea un régimen legal de protección exclusivamente para las parejas heterosexuales y por consiguiente se declarará la exequibilidad de la Ley 54 de 1990, tal como fue modificada por la Ley 979 de 2005, en el entendido que el régimen de protección alli previsto también se aplica a las parejas homosexuales".

¿Acaso la Ley 54 trata en algún momento la adopción de menores que puedan hacer estas parejas?, ¿por qué tenía necesidad la Corte, en su motivación, de mencionar la adopción de menores para una ley demandada que no regula sobre el particular?

\subsection{Introducción de la adopción por homosexuales}

Una ruta explicativa a para responder las preguntas presentadas en el acápite anterior puede encontrarse, si se examina la vía que ha tomado la plataforma de actores e interesados en que la homosexualidad sea jurídicamente considerada ante el ordenamiento jurídico positivo colombiano como una legitima posibilidad fundacional de vínculos familiares, por cuanto propusieron reiteradamente varias demandas e intervenciones ${ }^{5}$. Empecemos por observar cómo los argumentos de la C-075 aparecen luego en demandas posteriores y en las consideraciones que la Corte debe hacer. Para el supuesto de la adopción de menores por parte de personas homosexuales encontramos los cargos que se presentan contra la diferenciación sexual que trae la disposición del numeral 3 (parcial) del artículo 68 de la Ley 1098 de 2006 y contra el artículo 1 (parcial) de la Ley 54 de 1990, tal como fue modificada por la Ley 979 de 2005, lo que da lugar a una primera demanda que produce la sentencia C-802 de 2009. En esta sentencia, la Corte se declaró inhibida para hacer un pronunciamiento de fondo pues encontró en los cargos propuestos situaciones que no podrían llegar a resolverse con las peticiones presentadas, porque:

5 Respecto de cómo se presenta esta vía son ilustrativos los siguientes trabajos: Mauricio AlbarRAcín CABAllero, Corte Constitucional y movimientos sociales: el reconocimiento judicial de los derechos de las parejas del mismo sexo en Colombia, SUR Revista Internacional de Derechos Humanos, 14, en http://www.surjournal.org/esp/conteudos/getArtigo 14.php?artigo=14,artigo_01.htm. Fecha de consulta: 24 de agosto de 2014; Stephani Ordóñez y Maria Cristina Valencia, "Adopción por las parejas homosexuales: de la realidad social hacia el reconocimiento judicial", Precedente, 2 (2013), pp. 227-228. 
1. "Las distintas modalidades del control abstracto de normas implican que: 1. Extender, sin limitación alguna, el juicio de constitucionalidad a una norma que no ha sido objeto de demanda, no se ajusta estrictamente al procedimiento que sobre el particular consagran la Constitución y la Ley; 2. Esa ampliación de la competencia de la Corte, para pronunciarse sobre normas que no han sido demandadas, impediría el ejercicio de los derechos y mecanismos de participación que se han establecido en el procedimiento de control de constitucionalidad, porque, respecto de dichas normas, no habría oportunidad para la intervención de las autoridades comprometidas en la materia, ni de los ciudadanos interesados, ni se le permitiría al señor procurador presentar su concepto en cumplimiento de una de sus funciones constitucionales, y, 3 . De esta forma, respecto de esas normas, debido a este control oficioso, no se daría la necesaria controversia constitucional entre el demandante, los intervinientes en el proceso y el procurador general de la Nación, lo cual llevaría a la Corte a pronunciarse sobre cuestiones respecto de las cuales no se habría producido deliberación pública institucional previa”.

2. "La adopción conjunta por parejas homosexuales plantea, desde la perspectiva del menor, el problema de su inserción en un hogar en el que ambos padres tienen el mismo sexo. En orden a adoptar una decisión de fondo en torno a la demanda de inconstitucionalidad presentada contra el numeral $3^{\circ}$ del artículo 68 de la Ley 1098 de 2006, la Corte debe dar una respuesta jurídico constitucional a la anterior situación, la cual se desprende no solo de la disposición demandada, sino también de los artículos que contemplan la posibilidad de la adopción de un menor por el compañero o compañera permanente del padre o la madre biológicos, en relación con los cuales se advierte la existencia del mismo problema jurídico”.

3. “...no es posible pronunciarse sobre la adopción conjunta por parejas homosexuales, sin hacerlo simultáneamente sobre la posibilidad de que una persona adopte al hijo biológico de su compañero o compañera del mismo sexo. Sin embargo, en distintas de las intervenciones ciudadanas, así como en algunos de los conceptos científicos aportados por las universidades, se pone en evidencia la existencia de significativas diferencias entre las dos hipótesis, que si bien tienen un sustrato común en el ejercicio del rol parental de manera conjunta por una pareja homosexual, plantean también problemas jurídicos de muy distinta naturaleza, derivados precisamente, de esas diferencias fácticas (Así, por ejemplo, un menor puede vivir en un hogar homosexual con su padre o madre biológica y su compañero o compañera del mismo sexo, y la adopción comporta una decisión de quien ejerce la patria potestad, por oposición a la situación del menor cuya adopción se pretende por una pareja homosexual, ninguno de cuyos integrantes tiene vínculo de naturaleza biológica con él)”.

4. “...la relación que existe entre las dos hipótesis y el hecho de haber sido incorporadas, ambas, o, indistintamente, una u otra, en las intervenciones que obran en el expediente, aconsejarian explorar la posibilidad de hacer la unidad normativa. Sin embargo, por el otro lado, las notables diferencia fácticas 
y los disímiles problemas jurídicos que se derivan de las mismas, así como el hecho de que esas hipótesis no son claramente discernidas por los intervinientes, muchos de los cuales no aluden a alguna de ellas, y que el hecho de no haberse demandado expresamente las normas que regulan la adopción de un menor por el compañero o compañera permanente del padre o la madre biológicos, podría comportar una afectación del debido proceso si se optara por dicha unidad normativa, inclinan a la Corte por una decisión inhibitoria, que, como se ha dicho, es la que mejor garantiza el debido proceso".

Sobre la adopción por parejas homosexuales, en un recorrido argumentativo similar al del régimen patrimonial, se suscita otra demanda, se trata de la sentencia C-710 de 2012 que resuelve respecto de los cargos de inconstitucionalidad que se presentaron contra la expresión "moral" contenida en el artículo 68 de la Ley 1098 de 2006. En el comunicado de prensa de la Corte se dice que los cargos no ofrecieron certeza y se estructuran a partir de una interpretación subjetiva del precepto demandado y no guardan relación con su contenido. Y porque según dice el comunicado:

\begin{abstract}
"[No] resulta admisible por cuanto dentro de las atribuciones de la Corte Constitucional no está la de examinar la constitucionalidad de sus propias providencias. Además, la acción pública de inconstitucionalidad no procede para solicitar ni la modificación ni la aclaración de sentencias de control de constitucionalidad. En este orden de ideas, reiteró que el artículo 241 superior le confia la guarda de la integridad y supremacía de la Constitución, para lo cual fija a continuación sus funciones y competencias”.
\end{abstract}

Al parecer, la demanda le proponía a la Corte cambiar su precedente. ¿Sobre qué aspecto podría ser? La plataforma de actores e intervinientes partidarios de la demanda le solicitaban a la Corte modificar el contenido de sentencias anteriores en donde se había precisado el alcance de la expresión "moral" que, paradójicamente, les resultaba una expresión discriminatoria y sospechosa respecto de las personas que practican o promueven la homosexualidad, bajo el supuesto de que con tal expresión las autoridades pueden impedirles adoptar menores basadas, eventualmente, en sus conductas. Pero lo que sí aparece, como se verá más adelante, es que la declaratoria de inhibición que hace la Corte en su sentencia del examen de la expresión contenida en la norma que permitiría no obstaculizar la adopción de menores por parte de la persona que proyecta y ejerce prácticas homosexuales (individual o en pareja), no es sino una preparación argumentativa para un posterior examen que "blinde" de manera formalista la argumentación a favor de las pretensiones de la misma plataforma de demandantes. Esto, aun repitiéndose los mismos argumentos, con una forma distinta de enunciarlos, y que, según la misma Corte, los cargos de la demanda anterior no hayan ofrecido certeza, etc.

Lo anterior se evidencia cuando las exigencias que la ley pueda llegar a fijar para la idoneidad de un eventual padre adoptante se exponen a ser retiradas del ordenamiento jurídico mediante la fuerza formal que pueda tener un argumento ex- 
puesto en una sentencia inhibitoria, aun expuesto de forma tangencial, pero que pueda llegar a ser replicado de manera interpretativa en una sentencia posterior llamándolo "precedente", y para cuando la misma Corte aborde la cuestión de la heterosexualidad en el matrimonio o la de la idoneidad moral de los adoptantes: primero se inhibe diciendo que los cargos no ofrecieron certeza y se estructuran a partir de una interpretación subjetiva, etc., y luego, por las misma normas y cargos declare, como lo hizo en la C-577 de 2011, la necesidad de una protección especial constitucional para que estas parejas se asemejen al matrimonio, ordenando que si en un término de seis meses el Congreso no legisla, las parejas homosexuales acudan ante notario a celebrar su boda, aplicándoseles para el efecto las normas jurídicas relativas a los matrimonios.

Al momento de terminar el presente análisis, el Congreso de la República ha archivado las iniciativas legislativas que regulan las uniones matrimoniales para las personas del mismo sexo y la consiguiente adopción. Sin embargo, la Corte Constitucional colombiana, en el comunicado de prensa 35 del 28 de agosto de 2014 , anuncia la decisión de su sala plena de expedir una sentencia de unificación para las revisiones de tutela SU-617 de 2014, que con fundamento en su doctrina expuesta en la C-577 de 2011 ampara el derecho de una pareja de lesbianas a que sus prácticas no puedan llegar a ser consideradas por los jueces y la agencia nacional de adopción (ICBF) como impedimento para adoptar un menor como quiera que a ellas les asiste el derecho a la libre conformación familiar. La decisión, así anunciada, es la muestra clara de los propósitos de la Corte Constitucional anunciados en el presente estudio según los cuales esta Corporación transforma los supuestos jurídicos que el texto constitucional presenta y que identifican a las familias colombianas. La argumentación que emplea para hacerlo se analiza a continuación.

\subsection{El regreso al modelo del contrato matrimonial: hacia la C-577 de 2011}

Pese a que el artículo 42 de la Constitución Política es claro en presentar las uniones de hecho entre compañeros (more uxorio) y el matrimonio como figuras sobre las que se reconoce la fundación de vínculos familiares nucleares ${ }^{6}$, la cuestión de

6 Se transcribe de manera completa: "La familia es el núcleo fundamental de la sociedad. Se constituye por vínculos naturales o jurídicos, por la decisión libre de un hombre y una mujer de contraer matrimonio o por la voluntad responsable de conformarla. El Estado y la sociedad garantizan la protección integral de la familia. La ley podrá determinar el patrimonio familiar inalienable e inembargable. La honra, la dignidad y la intimidad de la familia son inviolables. Las relaciones familiares se basan en la igualdad de derechos y deberes de la pareja y en el respeto recíproco entre todos sus integrantes. Cualquier forma de violencia en la familia se considera destructiva de su armonía y unidad, y será sancionada conforme a la ley. Los hijos habidos en el matrimonio o fuera de él, adoptados o procreados naturalmente o con asistencia científica, tienen iguales derechos y deberes. La ley reglamentará la progenitura responsable. La pareja tiene derecho a decidir libre y responsablemente el número de sus hijos, y deberá sostenerlos y educarlos mientras sean menores o impedidos. Las formas del matrimonio, la edad y capacidad para contraerlo, los deberes y derechos de los cónyuges, su separación y la disolución del vínculo, se rigen por la ley civil. Los matrimonios religiosos tendrán efectos civiles en los términos que establezca la ley. Los efectos civiles de todo matrimonio cesarán por divorcio con arreglo a la ley civil. También tendrán efectos civiles las sentencias de nulidad de los matrimonios 
las uniones entre compañeros requiere volver a ser estudiada por la misma Corte, pues antes de estas sentencias sobre adopción por personas homosexuales la Corte Constitucional había propuesto otros precedentes en relación con las parejas homosexuales que no alcanzaban a terminar de aclarar la vía argumentativa para que estas puedan tenerse como fundadoras de los núcleos familiares. Entonces, se deberían terminar de adaptar algunos institutos del derecho de familia y de la protección social a las mismas en las uniones maritales para que también los esquemas matrimoniales puedan casar dentro del enfoque que concibe jurídicamente como beneficiosas a la familia las prácticas homosexuales. Téngase así una no muy breve sintesis:

1. Sentencia C-811 de octubre 3 de 2007 (M. P. Marco Gerardo Monroy Cabra). Mediante esta sentencia la Corte Constitucional declaró exequible el artículo 163 de la Ley 100 de 1993, "en el entendido (de) que el régimen de protección en ella contenido se aplica también a las parejas del mismo sexo". Ese "régimen" hace referencia a la cobertura familiar del Plan Obligatorio de Salud del régimen contributivo. En esta sentencia se resaltan las siguientes consideraciones:

a. "La perspectiva actual en el tratamiento jurídico del tema" de los derechos patrimoniales de las parejas homosexuales parte de la sentencia C-075 de 2007.

b. De conformidad con la mencionada sentencia, un "criterio de evaluación de la disposición acusada" es la "detección del déficit de protección”, pues la norma impugnada "también deja por fuera el alcance de la protección en salud a las parejas del mismo sexo. No obstante, dado que el régimen que ahora se demanda tiene que ver, no con los efectos patrimoniales de la unión de hecho entre parejas del mismo sexo, sino de su acceso a los servicios de salud, la Corte considera que el déficit de protección se presenta de manera más palpable”.

c. La exclusión de las parejas del mismo sexo, del Sistema General de Salud, no es necesaria para los fines previstos en la norma impugnada, "dado que la inclusión de la misma no implica la indefectible desprotección del núcleo familiar". A juicio de la Corte, "la detección del déficit de protección que afecta a las parejas del mismo sexo no necesariamente implica la reducción de beneficios a la célula familiar, ni la disminución de los niveles de atención a los miembros de la pareja heterosexual, por lo que no existe justificación alguna para señalar que una medida como la que ahora se impone involucre afectación de la protección que la Constitución ofrece en esta materia”. 
2. Sentencia C-336 de abril 16 de 2008 (M. P. Clara Inés Vargas Hernández). La Corte Constitucional, mediante esta sentencia, declaró exequibles las expresiones "la compañera o compañero permanente", "la compañera permanente"; "compañero o compañera permanente", "una compañera o compañero permanente" contenidas en el artículo 47 de la Ley 100 de 1993, modificado por el artículo 13 de la Ley 797 de 2007, y las expresiones "el cónyuge o la compañera permanente", contenidas en el artículo 74 de la Ley 100 de 1993, "en el entendido [de] que también son beneficiarias de la pensión de sobrevivientes las parejas permanentes del mismo sexo cuya condición sea acreditada en los términos señalados en la sentencia C-521 de 2007 para las parejas heterosexuales”. En esta sentencia se resaltan las siguientes consideraciones:

a. Que la Corte Constitucional, mediante sentencia C-075 de 2007 "estableció que el reconocimiento de determinadas garantias a las parejas heterosexuales puede corresponder a una forma de discriminación para las parejas homosexuales, cuando a estas no se les reconoce lo mismo sin suministrar una explicación objetiva y razonable”.

b. Que la Corte Constitucional, mediante la sentencia C-075 de 2007, reconoció respecto a la norma impugnada "una ausencia de protección en el ámbito patrimonial para la pareja homosexual”, en cuanto resulta lesiva de la dignidad humana y contraria al derecho al libre desarrollo de la personalidad y "comporta una restricción injustificada de la autonomía de los integrantes de tales parejas y puede tener efectos lesivos, no solo en cuanto obstaculiza la realización de su proyecto de vida común, sino porque no ofrece una respuesta adecuada para las situaciones de conflicto que se pueden presentar cuando por cualquier causa cese la cohabitación”.

c. Que la Corte Constitucional, mediante sentencia C-811 de 2007, hizo uso del criterio de "déficit de protección inadmisible a la luz de la Constitución" para extender a las parejas homosexuales el régimen de protección del Plan Obligatorio de Salud.

d. Que, "aunque la legislación positiva no establezca de manera expresa un determinado ámbito de garantías para la comunidad homosexual, ello no ha sido obstáculo para que en áreas específicas, como la relacionada con el régimen patrimonial de las uniones maritales de hecho y la cobertura del Plan Obligatorio de Salud, la jurisprudencia haya reconocido un tratamiento igual para las parejas heterosexuales y homosexuales".

e. Que el trato discriminatorio para las parejas homosexuales en cuanto al beneficio de la pensión de sobrevinientes implica que se "encuentren en un déficit de protección" contrario a la Constitución, "por cuanto no existe un fundamento razonable y objetivo para explicar el trato desigual al que vienen siendo sometidas las personas que en ejercicio de sus derechos al libre desarrollo de la personalidad y a la libertad de la opción sexual, han decidido conformar una pareja con una persona de su mismo género", razón por la cual ha 
de reconocérseles el derecho a acceder a la pensión de sobrevinientes en las mismas condiciones que tienen las parejas heterosexuales.

3. La sentencia C-798 de 2008 (M. P. Jaime Córdoba Triviño) declaró inexequible únicamente la expresión contenida en el parágrafo del artículo $1^{\circ}$ de la Ley 1181 de 2007 —relativa a la responsabilidad penal por el incumplimiento de la obligación alimentaria que corresponde al hombre y a la mujer que integran la unión marital de hecho, en los términos de la Ley 54 de 1990 y exequible "el resto de esta disposición en el entendido [de] que las expresiones 'compañero' y 'compañera permanente' comprenden también a los integrantes de parejas del mismo sexo". En esta sentencia se resaltan las siguientes consideraciones:

a. Entre los compañeros permanentes, con independencia de su orientación sexual, existe la obligación alimentaria, siempre y cuando que la pareja reúna los requisitos de que trata la Ley 54 de 1990, tal como fue modificada por la Ley 979 de 2005.

b. El criterio de la "sexualidad de las personas es completamente irrelevante a la hora de extender la protección patrimonial de los miembros de la pareja”, razón por la cual este criterio "no puede ser utilizado, al menos en principio y salvo alguna poderosa razón fundada en objetivos constitucionales imperativos, para diferenciarla”.

c. La obligación alimentaria hace parte del régimen patrimonial de la unión marital de hecho. Al ser, en consecuencia, "un aspecto del régimen patrimonial debe estar regulada, al menos en principio, de la misma manera en el ámbito de las parejas homosexuales y de las parejas heterosexuales”.

d. La Corte "ha establecido una doctrina coherente, consistente y reiterada, en virtud de la cual el déficit de protección de las parejas homosexuales en materia patrimonial no encuentra justificación constitucional alguna y debe ser corregido de conformidad con lo establecido por el artículo 13 de la Constitución".

e. La Corte, para el caso decidido por la sentencia C-798 de 2008, reconoció la existencia de un "tratamiento diferenciado en materia de derechos y deberes patrimoniales a los miembros de la pareja heterosexual respecto de los miembros de la pareja homosexual". Ese "tratamiento diferenciado" constituye, no solo "un notable déficit de protección en materia de garantías para el cumplimiento de la obligación alimentaria", sino un "tratamiento sospechoso", por lo cual su evaluación constitucional debe estar sometida "a un juicio de proporcionalidad estricto", a través del cual se determine "si la diferenciación legal persigue una finalidad constitucionalmente imperiosa y si es necesaria, útil y estrictamente proporcionada para alcanzarla. Si no fuera así, la ley estaría vulnerando, cuando menos, el principio de discriminación y debería merecer el correspondiente reproche de inconstitucionalidad". 
f. La extensión de la protección penal frente al incumplimiento del deber alimentario respecto de las parejas homosexuales "no tiene efecto, desde ningún punto de vista, [en] la disminución de la protección a los miembros de la pareja heterosexual".

4. Se destaca especialmente la sentencia C-029 de enero 28 de 2009 (M. P. Rodrigo Escobar Gil). En esta sentencia la Corte se declaró inhibida para pronunciarse de fondo en relación con las expresiones "familia" y "familiar" contenidas en el artículo 4º de la Ley 70 de 1931, modificada por la Ley 495 de 1999, y en el artículo $1^{\circ}$ de la Ley 258 de 1996, así como por los artículos $1^{\circ}$ y 27 de la Ley 21 de 1982, por ineptitud sustantiva de la demanda. Así también, se declaró inhibida para emitir un pronunciamiento de fondo en relación con la expresión "grupo familiar" contenida en el numeral 1 del artículo 179 de la Ley 599 de 2000, por ineptitud sustantiva de la demanda. Pero en cambio, en el mismo fallo, la Corte declaró la exequibilidad de algunas normas impugnadas, en el entendido de que las expresiones "cónyuge" (contenida en el numeral 1 del artículo 411 del Código Civil, así como en el numeral 1 del artículo 457 del mismo Código) y "compañero permanente" o "compañera permanente" se aplican también en igualdad de condiciones a las parejas del mismo sexo. La Corte también declaró la exequibilidad de las expresiones "compañeros permanentes", "unión singular, permanente y continua”, "compañera permanente" y "unión permanente" usadas en normas relativas al patrimonio familiar inembargable, a la obligación alimentaria, a los derechos de carácter migratorio para las parejas heterosexuales, a las que consagran la garantía de no incriminación en materia penal, penal militar y disciplinaria, el beneficio de prescindir de la sanción penal, a las circunstancias de agravación punitiva, a las que tienen como sujeto pasivo de los delitos al compañero o compañera permanente, a las que consagran derechos a la verdad, a la justicia y a la reparación de las víctimas de crimenes atroces, a las medidas de protección civil a favor de las víctimas de crimenes atroces, a las prestaciones en el régimen pensional y de salud de la fuerza pública, al subsidio familiar en servicios, al subsidio familiar para vivienda, al acceso a la propiedad de la tierra, a los beneficiarios de las indemnizaciones del SOAT por muerte en accidente de tránsito, a los limites al acceso y ejercicio de la función pública y celebración de contratos estatales en las que se excluía la protección a las parejas homosexuales. Los argumentos de la Corte para esta sentencia fueron:

a. Reiteró la línea jurisprudencial según la cual, de acuerdo con la Constitución: "está proscrita toda forma de discriminación en razón de la orientación sexual". "[E]xisten claras diferencias entre las parejas homosexuales y las parejas heterosexuales", por tanto, "no existe un imperativo constitucional de dar un tratamiento igual a unas y a otras". tección debida a los distintos grupos sociales y avanzar en la atención de aquellos que se encuentren en situación de marginación”. 
"[T]oda diferencia de trato solo es constitucionalmente admisible si obedece al principio de razón suficiente. Por lo tanto, en cada caso concreto se debe examinar si la situación frente a las parejas heterosexuales y las parejas homosexuales es asimilable, para luego entrar a definir si la diferencia de trato que establece una norma específica es discriminatoria”.

b. La Corte encontró: "que la totalidad de las disposiciones acusadas parcialmente sobre las que se pronuncia en esta oportunidad, no entrañan una discriminación de las parejas conformadas por personas del mismo sexo, como proyecto de vida en común, con asistencia reciproca y solidaridad entre sus integrantes".

c. Las parejas homosexuales tienen los mismos derechos, beneficios y cargas de las parejas heterosexuales: "si bien pueden existir algunas diferencias entre las parejas heterosexuales y las que conforman por personas del mismo sexo, ambas representan un mismo valor y una misma dignidad" y por tanto hay "unos requerimientos análogos de protección".

d. La exequibilidad condicionada de las disposiciones así declaradas la argumentó con afirmaciones como las siguientes: el artículo 13 constitucional establece una prohibición de discriminación y que al desconocer ese precepto constitucional las normas impugnadas, "la Corte procedió a excluir la interpretación violatoria del derecho fundamental a la igualdad de trato y en consecuencia declaró la exequibilidad condicionada de las normas impugnadas, en el sentido de que todas esas disposiciones comprenden también, en igualdad de condiciones, a las parejas conformadas por personas del mismo sexo".

Sobre el concepto de familia contenido en las normas demandadas la Corte no se puede pronunciar "como quiera que la demanda no se orienta a cuestionar el concepto de familia previsto en la ley", sino que "la situación de los integrantes de las parejas homosexuales de carácter permanente que aspiren a un subsidio de vivienda en atención a su condición de pobreza, es asimilable a la de los compañeros o compañeras permanentes", y "observa la Corte que los demandantes, aparte de la consideración sobre el efecto de exclusión que, en una determinada interpretación, podría derivarse de las expresiones 'familiar', 'familia' o 'familiares', contenidas en los artículos 80, 159, 161 y 172 de la Ley 1152 de 2007, no presentan un cargo específico de inconstitucionalidad contra las mismas, razón por la cual la Corte se inhibirá para emitir un pronunciamiento de fondo en relación con ellas”. Pero en lo que corresponda al "alcance restrictivo que en relación con las parejas homosexuales puede tener el artículo del que hacen parte las expresiones, la Corte se pronunciará sobre dicho artículo como una unidad normativa”.

Completado el panorama jurídico de los institutos del derecho de familia con el aspecto asistencial de protección social por parte del Estado, el concepto que el artículo 42 de la CP ofrece de la fundación heterosexual, y en especial su re- 
lación con la "restricción" que se piensa que podrían tener las leyes para que las prácticas homosexuales comprendan a las uniones matrimoniales, se retoma el planteamiento argumentativo (trato desigual injustificado, omisión legislativa relativa, vulneración de la autonomía reproductiva) pero abordando el matrimonio como contrato, así es necesario que la norma del artículo 113 del Código Civil no exija como elemento esencial al contrato de matrimonio: la monogamia, la heterosexualidad, apertura libre y voluntaria a la procreación.

De esta manera, no es necesario retomar la problemática argumentativa de las demandas y sentencias respecto a las uniones maritales y el régimen de extensión para las parejas que practican la homosexualidad, sino que se debe poner de presente lo que la Corte Constitucional dijo: que la relación matrimonial sirve de referente para las uniones maritales (more uxorio) por ser una forma de familia. Y si la práctica de la homosexualidad de una pareja origina vínculos familiares susceptibles de reconocimiento como la unión de hecho, ¿por qué no también respecto al vínculo del contrato matrimonial?

\subsection{Repeticiones al examen de constitucionalidad}

1. Abordaje por la sentencia C-886 de 2010. La Corte examina los cargos que se presentan contra el artículo 113 del CC en el que solicitan "se declare exequible la norma demandada en el entendido que también las parejas homosexuales pueden contraer matrimonio", y la expresión "procrear" contenida en el mismo artículo. Afirman que cualquier otra interpretación sería "inexequible". También, los cargos que presentan contra el artículo 2 de la Ley 294 de 1996 en relación con las expresiones "familia" y "de un hombre y una mujer", para que sean declaradas inexequibles. La Corte resolvió declararse inhibida para pronunciarse de fondo "por ineptitud sustantiva de la demanda". Los argumentos para la solicitud de los actores fueron, en sintesis, trato desigual injustificado, omisión legislativa relativa, vulneración de la autonomía reproductiva. Cuatro magistrados salvaron voto a la decisión de declaratoria de inhibición.

Pese a la declaratoria de inhibición, los salvamentos de voto que presentaron los magistrados María Victoria Calle, Juan Carlos Henao y Jorge Iván Palacio, y también el de Luis Ernesto Vargas, evidencian que la Corte sí tuvo en sus manos unos cargos con suficientes presupuestos para adoptar una decisión de mérito. Así, se encuentra que los magistrados disidentes mostraron que la posición mayoritaria de la Corte "eludió la discusión [...] a partir de argumentos diferentes a los contemplados por jurisprudencia reiterada en materia de admisibilidad de las demandas de inconstitucionalidad" (Vargas Silva); "[1]a sentencia, con los reclamos y los derechos invocados, exige unos inusitados estándares de admisibilidad que no se inspiran en el principio pro actione, sino en el que se vislumbra en el fallo, su contrario: el principio contra actione" (Calle, Henao, Palacio). Por el contrario, afirma uno de los disidentes: "el

112 actor presenta su demanda a partir de la metodología comúnmente aceptada por la Corte, como es la utilización de un juicio de proporcionalidad y la recopilación de reglas jurisprudenciales de los fallos del periodo 2007-2010, que 
han reconocido distintos derechos y garantías a las parejas del mismo sexo [...] Si la Corte exigiera no solo los argumentos que permiten construir ese problema constitucional, sino también que las conclusiones a las que llega la demanda sean compatibles o acordes con la visión de la mayoría de la Sala, entonces el Tribunal terminaría por requerir que la demanda propusiera, no un problema jurídico sustantivo, sino un proyecto de decisión sometido al posterior aval de la Sala. Esta postura es irrazonable y no tiene soporte normativo en las reglas que para el efecto prevé el artículo $2^{\circ}$ del Decreto Ley 2067 de 1991" (Vargas Silva).

En el salvamento de voto de los magistrados Calle, Henao y Palacio se adelanta además que "es, pues, comprensible el cargo presentado por los demandantes. En la medida en que el artículo 42 es una norma constitucional que consagra un derecho fundamental, en el contexto de un Estado social y democrático de derecho, fundado en la dignidad humana, es claro que puede ser interpretada de forma amplia. Es por ello que lejos de ser una opinión o una mera conjetura, es evidente que el texto constitucional no prohíbe el matrimonio de personas del mismo sexo. Y al ser una norma con las características mencionadas, también es claro que su interpretación puede ser extensiva e incluyente”. Ya para estos tres magistrados era válida la propuesta argumentativa de la demanda en el sentido que el ius connubi es un derecho fundamental del que goza cualquier persona independientemente de que su comportamiento afectivo sexual se proyecte o despliegue con otra o varias personas del mismo sexo.

Es más, la sentencia C-886 de 2010 consideró que para decidir de fondo en el planteamiento de dichos cargos era necesario precisar que las premisas de las que partían los demandantes carecían de sustento:

a. Si esa diferenciación contenida en la norma presentaba realmente un trato discriminatorio. Ya mencionamos el reclamo que hicieron los magistrados disidentes por esta postura mayoritaria. Ahora, sobre el particular, encontramos que en el análisis que se presenta en la sentencia los argumentos relativos al derecho a la igualdad, libre desarrollo de la personalidad, trato conforme a la dignidad humana, si se estudian al detalle:

\begin{tabular}{|l|l|}
\hline \multicolumn{1}{|c|}{ Proposición en la demanda } & \multicolumn{1}{c|}{ Respuesta de la Corte a la demanda } \\
\hline $\begin{array}{l}\text { El artículo 113 del Código Civil prohíbe al hombre o a la } \\
\text { mujer homosexual contraer matrimonio por causa de su } \\
\text { orientación sexual, y si quisieren contraerlo les obliga } \\
\text { a renunciar a su orientación y sin que se les pueda ga- } \\
\text { rantizar el derecho a su libre personalidad. }\end{array}$ & $\begin{array}{l}\text { En el texto de la disposición acusada "no se desprende la } \\
\text { regla según la cual un hombre o una mujer homosexual } \\
\text { deben hacer caso omiso a su orientación sexual para } \\
\text { contraer matrimonio; se está demandando una propo- } \\
\text { sición jurídica que no está presente y que por ende no } \\
\text { existe en la disposición legal acusada". }\end{array}$ \\
\hline & $\begin{array}{l}\text { "Los argumentos con base en los cuales se permita in- } \\
\text { ferir que la norma produce tratos inhumanos a un de- } \\
\text { terminado grupo de personas [...] son solo sospechas y } \\
\text { conjeturas radicadas en el parecer de quien demanda } \\
\text { pero que no permiten edificar un cargo de constituciona- }\end{array}$ \\
$\begin{array}{l}\text { lidad. Se insiste que el trato indigno, vil e indecente no } \\
\text { se desprende objetivamente de la disposición acusada, } \\
\text { sexuales de forma degradante". } \\
\text { y por tal razón no posee la certeza para estructurar el } \\
\text { cargo constitucional". }\end{array}$ \\
\hline
\end{tabular}




\section{Proposición en la demanda}

La norma demandada con respecto a los homosexuales "los cosifica, desconoce su dignidad humana y los obligan a renunciar a lo irrenunciable: la orientación sexual".

Cuando el artículo 42 de la Constitución presenta el vínculo de hombre y mujer como fundante de la familia "no excluye del matrimonio a parejas del mismo sexo, sino que se limita a reflejar una realidad social: que la heterosexualidad es mayoritaria en nuestro pais".

"El matrimonio señalado en la norma constitucional debería ser extendido a las parejas del mismo sexo”.

\section{Respuesta de la Corte a la demanda}

"Del artículo 113 del Código Civil no se desprende instrumentalización del ser humano. Por el contrario, dicho contrato está sustentado en el consentimiento y en la libertad del contrayente; facultades inherentes a un ser humano digno. Siendo así las cosas, la afirmación es inexistente en el contenido normativo acusado y traducido en falta de certeza. Ciertamente, se están extrayendo unos efectos que la disposición acusada no contempla y además la interpretación que se busca hacer valer no es plausible".

"El demandante realiza una valoración sobre los fundamentos de una norma constitucional, apreciación esta que no escapa de simple campo estimativo propio del accionante pero que no funda cargo constitucional alguno [...] Si la norma constitucional refleja o no una realidad del país, cualquiera que sea; no comporta un cargo contradictorio de la constitución sino una simple deducción subjetiva de quien la realiza".

"Es la exteriorización de un deseo de quien presenta la demanda; sin embargo, dicho afán no puede estructurar un cargo de constitucionalidad [...] mal podría entenderse dicho argumento como constitucional por cuanto escapa a la esfera jurídica para radicarse en una simple esperanza [...] así las cosas, no puede esta Corporación modificar una específica situación por el simple querer de quien demanda".

"Ha existido una interpretación errada del artículo 2 de la Ley 294 de 1996 que desarrolla el art. 42 de la Constitución (violencia intrafamiliar) ya que no es cierto que la familia siempre esté integrada o tenga en su base a un hombre y a una mujer. Se debe entender que la 'o' que se usa entre la hipótesis matrimonial y la de la voluntad responsable de conformarla, hace referencia a formas optativas de constituir una familia que pueden o no estar relacionadas entre ellas. Tratándose de un Estado social y democrático de derecho no se puede afirmar que la heterosexualidad sea requisito sine qua non en todas las clases de familias existentes en el marco de la sociedad, las cuales se encuentran igualmente protegidas por nuestra Constitución y qué, con base en ello, se pueda vulnerar el derecho de las parejas homosexuales a contraer matrimonio y conformar una familia en pro de las creencias particulares de un grupo mayoritario pues, con esos mismos argumentos, otras prácticas discriminatorias como el racismo y el sexismo se han abierto campo en nuestra sociedad".

"Cuando se habla de la posibilidad de que las parejas homosexuales puedan integrar un grupo familiar se incurre en el error de confundir la noción de familia, en estricto sentido, la institución religiosa del matrimonio y su particular concepción de familia".
Son meras suposiciones de los demandantes. "El actor acepta que la norma acusada no hace sino reproducir el precepto constitucional vertido en el artículo 42 de la Constitución. En este orden de ideas, expresa el demandante que se le ha dado una interpretación errada al artículo 2 de la Ley 294 por cuanto la familia no siempre está integrada por un hombre y una mujer. No obstante lo anterior, no se señala o indica qué juez o corporación judicial ha dado esta especial interpretación, en qué circunstancia concreta se ha realizado esta disquisición, qué entidad del Estado la ha hecho, careciendo por ende dicha indicación de la certeza necesaria”.

\footnotetext{
"De los razonamientos expuestas por el demandante se constata la tendencia a partir de la base de que el matrimonio y familia son lo mismo [...] se pregona que la afectación de los derechos de los homosexuales se produce ante la imposibilidad de contraer matrimonio o integrar el núcleo familiar. Dicho raciocinio carece de sustento objetivo en la norma constitucional [...] Es deber resaltar el hecho de que si el demandante acepta que la norma acusada lo que hace es reproducir un contenido normativo constitucional, en realidad lo que está haciendo es atacar de inconstitucional un artículo constitucional, tratando de demostrar una antinomia constitucional" (énfasis agregado).
} 


\section{Proposición en la demanda}

"La prohibición legal a los homosexuales de recurrir al contrato civil de matrimonio y a conformar una familia derivada de las normas demandadas viola en forma flagrante el derecho a la igualdad [...] encarna prejuicios y estereotipos que no tienen cabida [...] es indispensable recurrir a un test estricto de proporcionalidad en que se establezca si las restricciones a las parejas del mismo sexo a conformar una familia y a acudir al contrato civil de matrimonio tiene asidero en argumentos razonables o en simples consideraciones de carácter moral sin asidero constitucional".

"[L]as normas demandadas constituyen una vulneración al principio de dignidad humana toda vez que limitan la posibilidad de los homosexuales a tener un plan de vida y desarrollarse en forma plena, acorde es el deseo del espiritu humano".

Se vulnera el artículo 23.2 del Pacto Internacional de Derechos Civiles y Politicos: "el derecho del hombre y de la mujer a contraer matrimonio sin distinguir las circunstancias sexuales, raciales, de orientación sexual o cualquier otra de quien decide vincularse jurídicamente con su pareja".

"El poder construir una familia es un derecho humano universal reconocido [...] sin consideración alguna a la necesidad de una pareja o a la heterosexualidad de la persona, que encuentra apoyo en la apertura semántica del artículo 42 de la Constitución”.

"Es irrazonable, desproporcionado y ajeno que las personas homosexuales y demás integrantes de la población LGTB sean privadas del derecho a constituir un núcleo familiar o a recurrir a un contrato civil de matrimonio como forma asociativa".

"Si bien la posibilidad de permitir la adopción a las parejas del mismo sexo no es una de las pretensiones de la demanda, aunque deviene como consecuencia necesaria de la posibilidad de celebrar contrato civil de matrimonio, debemos reconocer que uno de los grandes obstáculos que ha existido para que las parejas del mismo sexo puedan acudir al contrato civil de matrimonio como forma asociativa y se puedan constituir como una familia ha sido el hecho de permitirles adoptar hijos".

\section{Respuesta de la Corte a la demanda}

"El razonamiento no es cierto por cuanto el demandante parte de una proposición jurídica inexistente, esto es, el hecho de que solamente a través del matrimonio se conforma una familia [...] posteriormente opta el accionante por describir las características de la pareja como forma asociativa para concluir que dichas particulares características hacen parte tanto de las parejas heterosexuales como de las homosexuales [...] no puede aceptar esta Corte como argumentos que sustenten la explicación de un test de proporcionalidad, razonamientos simplemente circunscritos al derecho de asociación y a las características de la pareja, que en realidad resultan ajenos e inconexos, a la estructura jurídica de un test de proporcionalidad en sede de igualdad".

"[E]l demandante solamente circunscribe la posibilidad de que las personas homosexuales tengan un plan de vida y se desarrollen en forma plena acorde con el espiritu humano si contraen matrimonio. Aseveración que además de no tener certeza, por no desprenderse de los textos acusados; tampoco es suficiente por ausencia de argumentación [...] dichas conclusiones [las del demandante] además de no estar contenidas en los textos acusados, nuevamente confunden en uno solo los conceptos de matrimonio y familia, lo cual deriva en la falta de certeza de la argumentación. Así las cosas, el actor basa su argumentación en interpretaciones subjetivas respecto de los alcances de las disposiciones acusadas y del texto constitucional".

Refiriéndose al caso (Kopf y Schalk vs. Austria), "no puede aceptarse que una especial y particular interpretación de una norma internacional conlleve necesariamente la existencia de un cargo de constitucionalidad. [...] En contravia de lo aseverado por el accionante, tribunales de derechos humanos han validado que de manera objetiva el texto internacional no obliga a los Estados al matrimonio de parejas homosexuales".

“...el accionante incurre en la confusión de necesariamente equiparar el concepto de matrimonio con el concepto de familia. En varias ocasiones esta Corte ha insistido en la presente providencia que si bien es cierto una de las formas constitucionales de constituir familia es el matrimonio, no es menos cierto que esta no es la única forma de hacerlo".

"De las normas acusadas no se desprende objetivamente, el señalamiento de una 'prohibición'. En efecto, el artículo 113 del Código Civil [...] no expresa objetivamente que la abstención pasiva de realizar una acción, en este caso la de contraer matrimonio"

"El actor fundamenta los razonamientos en una conjetura o sospecha personal según la cual [...] una de las causas por las cuales se impide el matrimonio de parejas homosexuales seria el hecho de permitirles adoptar hijos [...] se parte de apreciaciones personales o creencias del demandante en relación con las normas acusadas. Igualmente se pretende hacer valer la especial visión del accionante en la aplicación de la norma demandada o la manera como será empleada. En realidad, no se está acusando el contenido de la norma sino que está utilizando la acción pública para resolver un supuesto problema particular, como podría ser la aplicación de la disposición en un caso específico [...] la adopción no es un tema al que hagan referencia directa las normas demandadas". 


\begin{tabular}{|c|c|}
\hline $\begin{array}{l}\text { "El Estado constitucional no puede permitir la reducción } \\
\text { del contenido de un derecho fundamental al consenso } \\
\text { de una mayoria, lo que lleva a la injusticia, tirania y la } \\
\text { represión, antitesis clara de lo que debe ser un verda- } \\
\text { dero Estado Constitucional nuestro [...] existe un grupo } \\
\text { mayoritario que considera como contrario a la moral que } \\
\text { dos personas del mismo sexo formen una pareja y ten- } \\
\text { gan un proyecto de vida en común consistente en con- } \\
\text { formar una familia, [esto] no debe constituirse en obice } \\
\text { para que dicho derecho, constitucionalmente protegido, } \\
\text { les sea negado o desconocido ya que eso conlleva una } \\
\text { clara afrenta a los derechos fundamentales [...] la inac- } \\
\text { ción estatal frustra expectativas de bienestar y plenitud } \\
\text { garantizadas constitucionalmente a todos los colombia- } \\
\text { nos, sin lugar a ser discriminados". }\end{array}$ & $\begin{array}{l}\text { "Dicho razonamiento no posee certeza por cuanto surge } \\
\text { de la apreciación subjetiva del actor, según la cual se } \\
\text { está anulando un derecho fundamental por parte del Es- } \\
\text { tado debido a la presencia del consenso de una mayoria } \\
\text { [...] el accionante parte de una presunción o supuesto } \\
\text { propio según cual el Estado no reconoce el matrimonio } \\
\text { entre parejas homosexuales debido a que un grupo social } \\
\text { mayoritario lo considera contrario a la moral. En esta } \\
\text { providencia se ha afirmado que los anhelos o deseos } \\
\text { sociales no pueden constituir cargos de constituciona- } \\
\text { lidad debido a que carecen de la certeza indispensable } \\
\text { para emitir un pronunciamiento de fondo. [...] Al parecer } \\
\text { del accionante el hecho de poder procrear es una causa } \\
\text { para impedir el matrimonio de parejas homosexuales. } \\
\text { Aseveración no probada, que además carece de sustento } \\
\text { en la argumentación y que deviene exclusivamente de } \\
\text { su convicción intima”. }\end{array}$ \\
\hline
\end{tabular}

b. A pesar de lo claramente expresado en la C-886 de 2010, la literatura de algunos académicos en Colombia ${ }^{7}$ presenta estudios sobre los precedentes de la Corte Constitucional respecto de los reconocimientos de los derechos a la pareja del mismo sexo, pero omite mencionar la C-886 y los argumentos de ese fallo, y tampoco ofrecen motivos para sostener algún enfoque o perspectiva desde la que se permitan no considerar las discusiones y análisis de los magistrados, tanto a los cargos propuestos como a los argumentos de las ponencias mayoritaria y disidentes.

Precisando la decisión en la C-886 de 2010, la Corte consideró que todos los argumentos ofrecidos en la demanda correspondian a "una aspiración particular de ver que el Estado colombiano permita el matrimonio de parejas homosexuales", y afirma además que "en sede de constitucionalidad corresponde a la Corte Constitucional evaluar las posibles contradicciones de normas con fuerza de ley respecto de la Constitución, no es este el escenario estatal en el cual se debatan argumentaciones meramente políticas o sociológicas, sin que existan los razonamientos jurídicos mínimos de contradicción constitucional" . Por tanto "En el evento de que la Corte hubiere optado por pronunciarse en el presente caso hubiera terminado estructurando la base de la argumentación de su propia decisión. Sin duda, hubiere fungido como parte y como juez".

Analizando las respuestas ofrecidas por la Corte a cada uno de los cargos, no resultaría extraña la consideración que hacen los salvamentos de voto en relación con que la mayoría de magistrados (según las cinco disidencias) tenían

7 Por ejemplo: Manuel PÁEz Ramírez, "La sentencia C-577 de 2011 y el matrimonio igualitario en Colombia”, Revista Derecho del Estado (2013), en http://www.scielo.org.co/scielo.php. Fecha de consulta: 25 de agosto de 2014; Paola Ceballos Ruiz et al., "El reconocimiento de las parejas del mismo sexo: el camino hacia un concepto de familia pluralista", en Estudios Sociojurídicos (2012), en http://www.scielo.org.co. Fecha de consulta: 25 de agosto de 2014; Jaime Alfonso CuBIDEs, "El rol de 116 la jurisprudencia de la Corte Constitucional en los derechos de las parejas del mismo sexo (PMS)", Revista Jurídicas, 9-1 (2012), pp. 61-79. Jackeline HernándEz P. y Aroldo Quiroz M., "Aspectos procesales sobre los derechos de las parejas del mismo sexo”, en Criterio jurídico garantista, 3 (2011), pp. $158-173$. 
ante sî los suficientes elementos de juicio para un fallo de fondo, y que no se dio sino que mayoritariamente se votó por la inhibición. De hecho, en los argumentos con los cuales responden en sana lógica se encuentran los implícitos motivos adversos a las solicitudes del demandante. Entonces, ¿bajo qué "lógica" podría justificarse que la decisión mayoritaria, además de considerar carentes de claridad, pertinencia y suficiencia los cargos propuestos, se inhiba de pronunciarse sobre el fondo del asunto, si, observando la misma presentación de la demanda contenida en la parte motiva de la decisión, junto con las respuestas y las afirmaciones que hacen los magistrados disidentes, encontramos argumentos jurídicos (señalamientos de normas constitucionales y del bloque de constitucionalidad, apelación a principios del derecho, análisis de ponderación y precedentes decisionales) de la misma Corte en relación con las parejas homosexuales?

Al conocerse la decisión por el comunicado de prensa la cuestión es oscura, y, más todavia, cuando mucho tiempo después se publica el texto de la sentencia y luego se publican los salvamentos de voto. Quizá si nos adelantamos en el tiempo y llegamos a la C-577 de 2011, en la que encontramos el mismo examen normativo de constitucionalidad, los mismos argumentos presentados para la demanda que dio origen a la C-886-2010, y ante los mismos magistrados, pero con diferente decisión, y teniendo presente la perspectiva de cómo se producen cambios de jurisprudencia en la Corte Constitucional de los últimos años cuando realiza los controles de constitucionalidad ${ }^{8}$. Algunos estudios recientes observan que respecto a estos fallos puede existir un afán de protagonismo decisionista, argumentación sociologizante, superficial e ideológica ${ }^{9}$. Quizá con el trascurso del tiempo algún magistrado disidente ofrezca algunas pistas o testimonio de lo que sucedió para poder empezar a conjeturar y para entender la "lógica" de la Corte Constitucional que, en este periodo de su existencia histórica, viene tomando decisiones relativas a la familia.

2. La sentencia C-577 de 2011. Antes de presentar soluciones a las conjeturas observemos la C-577 de 2011, mencionada anteriormente. Los actores que se presentan son de la misma plataforma ideológica de aquellos de la demanda que dio como resultado la C-075 de $2007^{10}$. Han pasado desde entonces al

8 Se encuentra recientemente explicado por Fabio Enrique Pulido Ortiz y Jenny Carolina Burgos, "Valor epistémico de la democracia y jurisprudencia de la Corte Constitucional colombiana", Estudios de Derecho y Gobierno, 2-2 (2010), en http://portalweb.ucatolica.edu.co/easyWeb2/files/54_10647_ valor-epistemico-democracia-.pdf. Fecha de consulta: 2 de septiembre de 2014.

9 Cfr. Javier Tamayo J., Hermenéutica constitucional y legal (pro manuscrito), en http://www.eleccionvisible.com/doc/ternas/CSJ/T1_JTJ/T1_JTJ_LIBRO.pdf. Fecha de consulta: 2 de septiembre de 2014; Beatriz Eugenia Campillo Vélez, "La ideología de género en el derecho colombiano", Dikaion, 21-2 (2012), pp. 13-54, en http://dikaion.unisabana.edu.co/index.php/dikaion/article/ view/2784/3242. Fecha de consulta: 3 de septiembre de 2014; Gabriel Mora Restrepo, "La deformación de la práctica jurídica contemporánea: el oficio del jurista en medio de los ideólogos”, Dikaion, 21 (2012), pp. 333-336, en http://dikaion.unisabana.edu.co/index.php/dikaion/article/ view/3212/3062. Fecha de consulta: 2 de septiembre de 2014.

10 Respecto de la C-577 de 2011, Expediente D-8367: Carlos Andrés Echeverry Restrepo; Expediente D-8376: Marcela Sánchez Buitrago, Rodrigo Uprimny Yepes, Luz María Sánchez Duque, Diana Esther Guzmán Rodríguez, César Rodríguez Garavito, Mauricio Noguera Rojas, Felipe Montoya, 
menos tres años, aunque intervinieron en el debate que dio como resultado la decisión de la C-886 de 2010, y han intervenido en otras acciones públicas de inconstitucionalidad relacionadas con la familia y las diferenciaciones que las normas legales presentan respecto al género.

Para entender las consideraciones de la C-577 de 2011 es necesario examinar la formulación que hacen los demandantes. La demanda propone la idea de que en la pareja homosexual existen unos "vínculos" que dan origen a la familia. La demanda no habla de un tipo de vínculo, sino sencillamente de "vínculos", y tampoco los explicita. Propone que si el artículo 42 hubiera establecido una restricción para que la única forma de constituir vínculo matrimonial fuera la heterosexualidad, la redacción hubiese sido diferente: la Constitución no dice que el matrimonio solo se puede celebrar con una persona del sexo opuesto. Para los demandantes la única expresión que podría permitir entender que el vínculo matrimonial es heterosexual tendría que ser así, porque para estos la única expresión del artículo 42 que caracteriza al matrimonio es la de la decisión libre. Así se lee en la demanda: "el constituyente quería ampliar el espectro de las parejas que quieren que la legislación civil les reconozca el matrimonio y no circunscribir tal institución, únicamente a las parejas heterosexuales". Pues lo contrario supondría una violación del "núcleo esencial del derecho a la libertad [...] las decisiones libres no pueden predicarse solamente de las parejas heterosexuales, ni el Estado puede reconocer jurídicamente solo las decisiones manifestadas por dichas parejas, pues estaría protegiendo e incentivando un trato discriminatorio con los homosexuales".

Respecto del término "procrear", la demanda 1 dice que es discriminatorio y degradante para las parejas homosexuales. La expresión deberá declararse "inexequible", y declarar una "omisión legislativa relativa" en la relación de la expresión "un hombre y una mujer" con la de "procrear", condicionando simultáneamente la exequibilidad condicionada de los artículos 2 de la Ley 294 de 1996 y 2 de la Ley 1361 de 2009, en el sentido que se entienda que "la familia se constituye por vínculos naturales o jurídicos, por matrimonio o por la voluntad responsable de conformarla”.

Llama la atención que, pese a la transcripción literal que el artículo 2 de la Ley 1361 hace del artículo 42, en el sentido de modificar una trascripción literal del mismo texto constitucional, ¿acaso los demandantes están solicitando que la Corte intervenga en el sentido y alcance de un norma constitucional, modificando algo de lo que esta misma norma prescribe? Puede que sea cierto que el asunto depende de cómo se interprete una norma de textura abierta, pero lo que sí se evidencia con esta solicitud es que los demandantes reconocen que tal expresión contenida en el artículo 42 de la Constitución Política (con todo y lo abierta que sea) no es conforme con sus pretensiones, pues de 
lo contrario no tendría sentido que solicitaran una lectura y sentido distinto a unas expresiones que no son otras que las contenidas en el mismo artículo 42 de la Constitución Política.

También solicitan los demandantes que, en virtud del principio de unidad normativa y de igualdad, se haga un condicionamiento general en el sentido de que toda ley que haga referencia a los cónyuges se aplique para la pareja de homosexuales; la expresión literal que se pide es: "los cónyuges e integrantes casados de las parejas del mismo sexo”. ¿Qué diferencia puede existir en el concepto cónyuge e integrante casado? ¿El vínculo matrimonial tiene acaso grados? ¿No existe una igualdad jurídica de la pareja matrimonial de manera que se impiden los tratos según grados de la relación? Al parecer, el literalismo (cónyuge $v s$. integrante casado) al que apostó esta última solicitud terminó siendo mucho más hermético que aquel literalismo que reprochan los mismos demandantes de las interpretaciones que la Corte Constitucional ha venido haciendo del artículo 42 superior. Y si acaso lo consideraron como un sinónimo, quizá no cayeron en cuenta que para el literalismo, la sinonimia no es una técnica legislativa confiable.

La demanda plantea la solicitud subsidiaria a las anteriores con una decisión condicionada con efectos diferidos, y reconociendo la "libertad de configuración del legislador" sobre el matrimonio pide que se le "conceda" un plazo de seis meses a fin de regular el matrimonio para parejas del mismo sexo, precisando que si no existe una nueva regulación "debe entenderse que rige plenamente el derecho de las parejas del mismo sexo a contraer matrimonio, con base en la regulación vigente y los condicionamientos hechos por la Corte". De la solicitud cabe preguntarse - además de los cuestionamientos que puedan hacer expertos constitucionalistas sobre la libertad de configuración del legislador en estas materias- que si la pretensión principal comprende un condicionamiento, por tanto, ¿qué tan subsidiaria puede ser una solicitud que plantea el mismo condicionamiento dicho en la pretensión principal?

\subsection{La génesis del argumento formalista}

A cuenta del control abstracto de constitucionalidad a las normas demandadas, la argumentación que examine una norma no puede ser monádica.

En el caso de examinar si una norma crea situaciones de desigualdad, es necesario precisar las condiciones de la discriminación y su alcance frente a la justicia de la misma norma. La Corte examina una discriminación que solo los demandantes suponen pero que la norma no proyecta. La relación hombre y mujer que se caracteriza en las definiciones normativas de la unión marital o del matrimonio no marca o proyecta un diferencial distinto al de su misma realidad: unión heterosexual con unos fines específicos. Sería como suponer que existe una discriminación desconsiderada o injusta en la definición que una norma tenga respecto a un instituto jurídico: piénsese, por ejemplo, en la compraventa, la que se define esencialmente como un intercambio de una cosa por un precio, y que por no 
incluir en la definición de la norma otras realidades distintas a la compraventa, v. gr. un arrendamiento, el legislador excluyó la posibilidad de que en los intercambios, que suceden en uno u otro instituto puedan aplicársele disposiciones o criterios análogos. Al suponer así una discriminación, la Corte desconoce el carácter meramente instrumental que tiene toda norma legal, imponiendo una carga al redactor de la misma, y que consistiría en obligarlo a que en toda definición legal deba precisar, en su texto, todas las posibles situaciones que puedan llegar a requerir una aplicación o referencia a la misma, so pena que pueda llegar a ser aplicada de manera desconsiderada por ser sospechosa de alguna forma de injusta discriminación. Si bien es cierto que toda definición discrimina, lo es porque desde cualquier lógica tal discriminación no es otra que la caracterización de una realidad. El absurdo consiste en sostener que las caracterizaciones contenidas en una norma conllevan necesariamente injustas discriminaciones en la vida real. Y es ese absurdo el que vale como criterio, en la argumentación de la Corte, y que motiva su decisión. Y como es un prejuicio que tacha de discriminatoria cualquier regulación o amparo a la opción de vida heterosexual por el solo hecho de ser distinta a la homosexual, la única prueba que presenta la motivación es la de la simple distinción que trae la norma. Y el único punto de comparación para presentar la supuesta injusta discriminación es el mismo prejuicio del que se toma el punto de partida (análisis monádico).

En consecuencia, los supuestos discriminatorios que trae la norma supondrian una violación al derecho de igualdad, no evidenciada desde situaciones reales en las que pueda llegar a aplicarse el dispositivo, sino desde la consideración abstracta de una supuesta discriminación, y que en sentencias anteriores también lo declaran. Así, sumando el consecutivo de las sentencias en las que se argumenta con una misma forma de análisis monádico respecto de la igualdad de trato, termina siendo la forma de análisis el argumento que más pesa, y no como tal el estudio realístico de cada uno de los derechos que pudieran llegar a conculcarse. Desde ahí se puede entender que la Corte no haya considerado necesario, en su motivación, contrastar los estudios que se le presentaron respecto a las dificultades que tiene proyectar una relación matrimonial entre homosexuales hacia las condiciones para la adopción de menores de edad-desconociendo que, si se trata del derecho a la igualdad, se deben concretar más aún los supuestos discriminatorios para situaciones que puedan llegar a ser reales y no supuestas desde un punto de comparación monádico.

El argumento que encuentra justificación en la forma de análisis (que haya sido incluido en una sentencia anterior o en un concepto matemático del derecho a la igualdad), viene de la forma y a partir de la misma es susceptible de circularidad y acomode. Así, por ejemplo, si en una sentencia la Corte declara la inexequibilidad de una norma que regula algún aspecto de la definición del contrato de arrendamiento, así también el mismo examen deberá surtirse con las normas que regulen el contrato de compraventa, porque al asemejarse al arrendamiento se considera que debe aplicarse el mismo análisis, y no porque realmente se 120 examine cómo puede darse la violación real de algún derecho fundamental con la aplicación de los supuestos que contiene la norma de la compraventa, que es 
posteriormente acusada. Y solo es la similitud de una situación jurídica analizada en una sentencia previa la que atribuye el valor argumentativo, y no el examen de fondo ante las situaciones vistas por la norma en sí misma que, posteriormente, vayan a examinar.

Así también, en este estudio se encuentra que:

1. Las ilaciones argumentativas comienzan en las sentencias inhibitorias en cuya parte motiva se ofrece el argumento formal (como si fuera un "soplo" o ligera indicación), ese mismo argumento se presenta en una posterior demanda para un "nuevo examen", es decir, para que la Corte lo avale como argumento a tenerse en un pronunciamiento de fondo, ofreciendo la construcción de un supuesto nuevo argumento terminado. Finalmente, el nuevo argumento se debe tener como precedente judicial del órgano garante de la Constitución Política. Y el argumento se valida como si fuera el mismo supuesto normativo que hubiera podido tener el legislador cuando creó la norma jurídica, que en este caso sería tomar las relaciones de personas que practican la homosexualidad como relaciones que conforman el vínculo familiar en razón de un principio de igualdad considerado en abstracto.

2. Igual que en los análisis anteriores a la C-577, la ilación argumentativa con respecto a la igualdad ha sido abstracta, proyectando situaciones hipotéticas y dándole un alcance a las normas demandadas de supuesto efecto discriminatorio, sin especificar en concreto por qué lo tienen, como si en el ordenamiento jurídico colombiano no existieran principios, jurisprudencia ordinaria y normas legislativas a las que cualquier operador jurídico pudiera referirse en cada caso para resolver necesidades patrimoniales de aquellas personas que establecen vínculos de solidaridad, distintos de las relaciones familiares. Pues la igualdad de trato como derecho se entiende que abarca situaciones o condiciones jurídicas asimilables, no por la ilación de argumentos formales, sino por la realidad de la relación personal que se da.

3. Como se ha venido anotando desde los primeros análisis que hacen las sentencias, frente a los reclamos de trato discriminatorio por regulaciones generales que traen las leyes colombianas respecto a vicisitudes en las relaciones familiares, a la Corte se le someten a su consideración supuestos panoramas socioafectivos. La Corte declara que se presentan interpretaciones subjetivas del alcance normativo de las disposiciones demandadas. Las demandas, además de consideraciones en juicios abstractos de ponderación, describen supuestas situaciones a las que las parejas que practican la homosexualidad podrían estar expuestas, bajo el supuesto de asimilar la vida de una pareja heterosexual que se propone en su relación establecer un vínculo familiar. Parecería que la apuesta de los demandantes es que las parejas que practican la homosexualidad tomaran como modelo las dinámicas de las parejas heterosexuales que fundan vínculos familiares. ¿Si tan necesario es que el ordenamiento jurídico respete las diferencias, por qué tendría que asimilarse una realidad con otra aun siendo tan distintas? ¿Puede hacerlo la mera fuerza de un argumento formal? 
Es por el derecho a la igualdad presentado en abstracto por donde circulan las argumentaciones, sin considerar las particularidades reales y presentes entre las personas que practican la homosexualidad en condiciones afectivas de posibles relaciones solidarias.

Existen reveladores estudios desde varias fronteras del conocimiento en los que se hace patente que las formas de solidaridad que vivencian las parejas homosexuales no pueden ser equiparadas con los mismos baremos que emergen de las parejas heterosexuales constitutivas de vínculos familiares. Y no por la vía de una necesaria referencia a los vínculos que puedan darse con menores procreados o puestos bajo su cuidado ${ }^{11}$. La complementariedad de la pareja heterosexual aporta a sus mismos integrantes expectativas de trato diferenciado, no por determinados roles que desempeñen, sino por las dinámicas de las prácticas sexuales que van más allá de la satisfacción de expectativas emotivas y solidarias ${ }^{12}$.

En efecto, la sexualidad heterosexual (perogruyo forzadamente necesario para quienes tomen la sexualidad solo desde uno de sus aspectos: la emotividad) no solo proyecta una predisposición natural a la fecundidad procreadora, se caracteriza también porque el reconocimiento del otro en sus genuinas expresiones sexuadas (corporalidad) representa un desafio personal que aprovecha los condicionamientos de reafirmación del propio yo, haciendo del compañero o cónyuge su complemento y motivo permanente de autoestima, por la apertura que se desencadena. De manera que su condición personal de sujeto expectante de un otro, siempre distinto de sí mismo, termina siendo satisfecha. Siempre y cuando el otro no llegue a ser instrumentalizado por las agencias que provienen del psiquismo humano en razón de los mismos condicionamientos de reafirmación del propio yo, o la llamada también cosificación del otro. Es decir, las dinámicas sexuales demandan el ejercicio de un autodominio según un orden que ofrece la condición genuinamente sexuada de quien resulta ser diferente. La relación mujer-varón ofrece unas condiciones únicas en el sentido expuesto, que históricamente, y bajo los sistemas jurídicos y morales de las civilizaciones, se han venido reconociendo en instituciones como el matrimonio y los vínculos con la prole del mismo.

Respecto de las parejas homosexuales, la Corte Constitucional colombiana y los demandantes mencionados no parece que hayan considerado las relaciones homosexuales bajo la perspectiva antropológica que evidencie la realidad de sus dinámicas y expresiones propias. Curiosamente, el prisma empleado es el de la abstracta y lingüísticamente aislada norma impugnada, con sus posibles aplicaciones a la pareja heterosexual, trasladando situaciones propias de una hacia las otras.

11 Universidad Austral, Matrimonio Homosexual y Adopción por parejas del mismo sexo, informe de estudios científicos y jurídicos, experiencia en otros países, 2010.

12 Natalia López Moratalla, Cerebro de mujer, cerebro de varón, Madrid, Rialp, 2007, pp. 103-119. 
Parece que ni la Corte ni los demandantes consideran que la solidaridad proviene de vínculos que no necesariamente se supeditan a las orientaciones afectivo-sexuales, la familia no es el único ámbito social en el que las relaciones entre personas son solidarias. El ordenamiento jurídico colombiano, en todas sus manifestaciones del sistema jurídico positivizado, es lo suficientemente abierto para que tanto los ciudadanos como los operadores jurídicos tengan a su disposición una pluralidad de acciones judiciales y reglas jurídicas para que una pareja, trío o cuarteto de homosexuales puedan resolver sus controversias patrimoniales sin ningún resquemor, incomodidad o sospecha de la buena fe con la que establecieron su relación solidaria. Y sin necesidad de asimilar lo que no es asimilable.

Aunque no sería ajustado por el momento enfocar la problemática mirándola exclusivamente a través de las decisiones de la Corte, es necesario considerar también que, cada vez que la Corte Constitucional colombiana examina la exequibilidad de normas jurídicas sobre la familia, bajo los supuestos de la homosexualidad, le presentan estudios desde metodologias que no incluyen perspectivas y marcos teóricos antropológicos o sociológicos distintos a los que proyectan solo emotividades de la heterosexualidad y de la homosexualidad, sin abordar las exigencias concretas del tipo de relación. Aunque no sería este el espacio adecuado para un completo metaanálisis de los mencionados estudios, la no consideración de otras perspectivas revela al menos que existe un sesgo, que si bien la Corte o los demandantes en cualquier otro asunto podrían llegar a calificar de entrada como "criterio sospechoso" cuando cuestionan o examinan una norma jurídica planteada para las parejas heterosexuales, pero que en lo que corresponde a la comprensión del fenómeno de la llamada orientación afectivo-sexual realizada, pretermite a propósito perspectivas antropológicas o sociológicas o la descalifican sin mayor análisis explícito. Ello sí que podría también verse como un criterio sospechoso, pero no sobre la norma jurídica examinada, sino sobre la motivación que da como resultado una nueva norma creada a partir de la decisión de la Corte Constitucional.

4. Como la Corte Constitucional de su propia mano no puede hacer explícito un eventual criterio que pudiera ser catalogado como "sospechoso", según el otro sentido anteriormente expuesto y contenido en la motivación de su decisión, remedio es soplar a los actores motivos que al parecer de los mismos magistrados podrían llegar a tomarse como plausibles para ellos mismos, si se les repite la oportunidad de pronunciarse sobre la misma temática. Al no presentarse en las primeras demandas las razones que permitirian a los magistrados tomar una decisión favorable, los fallos respectivos tendrán que ser inhibitorios. Pero ya habiendo indicado la manera de obtener una decisión favorable a través de los mismos motivos que los magistrados han indicado para justificar la forma de un "nuevo examen", ofrecen así las condiciones formales para que los actores, mediante la proposición en una nueva demanda, lo hagan, eludiendo así cualquier señalamiento inicial de sospecha hacia la mismos magistrados que alguna vez presentaron sus argumentos supuestamente inhibitorios. De los argumentos soplados no resulta relevante si son de 
la ratio $\mathrm{u}$ óbiter, igualmente se examinan favorablemente pues ya han entrado en las lineas argumentativas o "de pensamiento" de la Corte. Y, por tanto, tampoco cabría sobre ellos endilgar un examen superado por la cosa juzgada constitucional. Así ocurrió con la génesis de la sentencia C-577 respecto de la C-866, y también con los precedentes relativos a las necesidades de protección patrimonial de las parejas del mismo sexo, por cuenta del control abstracto a la legislación en materia de las uniones de hecho y la seguridad social.

Figura. "La propia cosecha de un argumento formalista".

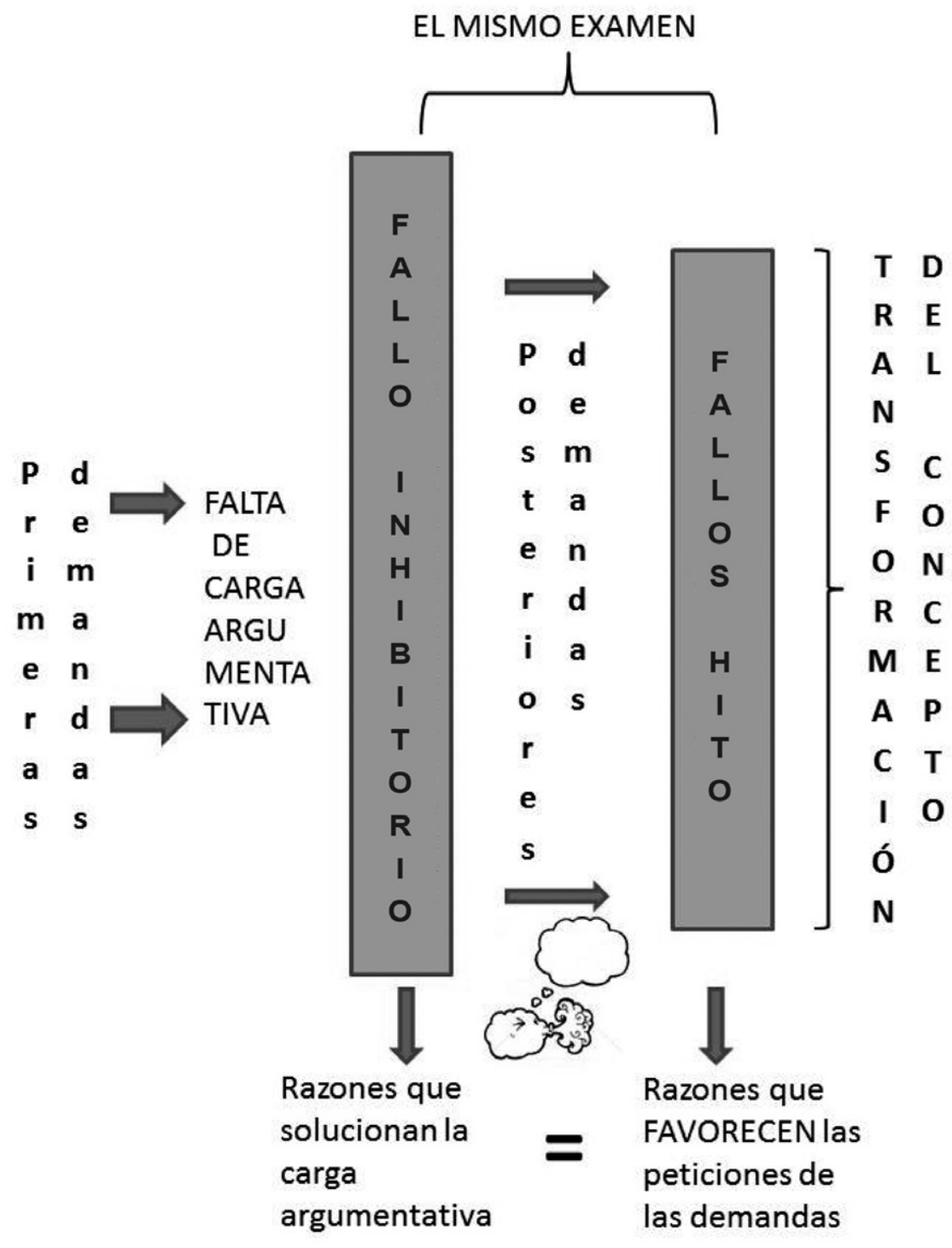

Fuente: Elaboración del autor. 


\subsection{La ratio de la C-577 de 2011: las apreciaciones globales}

Entonces, para llegar a individuar la línea argumentativa que da origen a la ratio decidendi de la sentencia C-577 de 2011, bastaría hacer una correlación de los argumentos soplados en las sentencias que preceden y, junto con elementos de plausibilidad aprioristica, presentar la necesidad en una perspectiva juridificadora de la equiparación de las relaciones familiares entre parejas heterosexuales con las relaciones entre parejas que practican la homosexualidad en cualesquier supuesto que un actor o demandante proponga. Trabajo que no requiere mayor sistemática o percepción completa de la realidad jurídica, sino agudeza de análisis formal en un acopio de argumentos que bastaria recoger con buscadores de palabras en un computador. A continuación se retoman los argumentos y se individualiza una ratio decidendi que sea respetuosa de una línea argumentativa de la Corte. Se muestra así como la Corte, en los juicios de constitucionalidad de las normas demandadas, consigue que la forma del argumento dé origen a nuevas formas argumentativas. Pero no parece que la Corte Constitucional colombiana, frente a los supuestos de las reclamaciones de actores respecto de regulaciones legales para parejas que practican la homosexualidad, y hasta el momento, abra sus análisis y exámenes a consideraciones menos abstractas y formalísticas, como por ejemplo, aquellas que observan los fenómenos particularizándolos por sus propias dinámicas antropológicas y sociales, y sin suponerlos o extraerlos de contextos creados por una determinada literatura. Tampoco parece que tomen en consideración estudios desde enfoques y perspectivas distintos a los empleados en los argumentos de los actores de dichas demandas.

1. La ratio decidendi de la sentencia C-577 de 2011. En efecto, la sentencia menciona que las demandas ofrecen "apreciaciones globales" que merecen ser consideradas como un nuevo cargo no comprendido en anteriores análisis a las normas, pues "las ubican en un contexto diferente del que ya la Corporación tuvo oportunidad de apreciar". Las apreciaciones globales serian:

a. Que en las nuevas demandas no se confunde matrimonio con familia. La Corte reconoce que en la sentencia inhibitoria anteriormente correspondiente a la C-577 de 2011, la C-886 de 2010, se advirtió tal "confusión" y ello le obligó a inhibirse de tomar una decisión de fondo en razón de que el cargo no fuera adecuadamente planteado. Obsérvese cómo entiende la Corte la mencionada "confusión":

A pesar de que lo diga la C-577 de 2011, la demanda que diera origen a la C-886 de 2010 no confunde matrimonio con familia, por el contrario, dice que hacerlo así sería un error: "...cuando se habla de la posibilidad de que las parejas homosexuales puedan integrar un grupo familiar se incurre en el error de confundir la noción de familia, en estricto sentido, la institución religiosa del matrimonio y su particular concepción de la familia" (citado de la demanda en el mismo cuerpo de la sentencia C-886 de 2010). Pero la Corte, tanto en la sentencia C-886 como en la sentencia C-577, considera que sí hubo tal confusión, tomando una afirmación del demandante que a continuación se cita: 
"Las normas demandadas al restringir sin fundamentos objetivos y razonables derechos fundamentales de las personas homosexuales contrarian este postulado básico que la Corte nos pone de presente y han dado origen a un sistema legal discriminatorio con efectos adversos para todas las personas que, atraídas por individuos de su mismo sexo, ven irrazonablemente obstaculizado su plan de vida al no poder contraer matrimonio civil o integrar un núcleo familiar como consecuencia de un marco legal del que son claramente excluidos y en virtud del cual son discriminados" (folio 40, Expediente D-7909 según se cita en la C-886 de 2010).

Es claro que el demandante pone de presente la exclusión de un "marco legal" como el matrimonial que se le hace a las parejas que practican la homosexualidad, de manera que se propicia así una discriminación desproporcionada, y no tanto una confusión entre matrimonio y familia. ¿Cómo llegó la Corte a entenderlo así? Un argumento que se suele ofrecer cuando se cuestiona el hecho de que exista una norma constitucional que defina la familia es el de pretender que la norma del artículo 42 abarque dentro de sus supuestos otras situaciones que son más manifestaciones de la vida familiar, que formas de constituirla. Por ejemplo, las manifestaciones que se dan por formas de monoparentalismo o ensamblaje. Es claro que la definición del artículo 42 no las expresa literalmente, y no porque no las reconozca como familias, sino porque la norma da una definición de las formas como proyecta la fundación original de la familia a partir de la voluntad de dos seres humanos con unas características, proyectos y responsabilidades solidarias. Desde las mismas actas de la Asamblea Constituyente que dio el texto de 1991, el artículo 42, sin tanto literalismo, muestra el proyecto mismo constitutivo de la realidad familiar que se origina de una pareja heterosexual. Parece que la Corte se resiste a reconocer ese sentido en el que se apoya la redacción del artículo 42. Y lo que de él entiende simplemente es que la heterosexualidad en las definiciones o proyecciones de las relaciones familiares es siempre "un criterio sospechoso" que requiere de un "test estricto de proporcionalidad" hecho por ella misma y los demandantes que "corrija” la redacción del artículo.

b. Que las demandas presentan "la evolución de la jurisprudencia constitucional sobre parejas del mismo sexo" respecto de la definición de homosexualidad por la necesidad que tienen estas parejas de que su relación sea protegida por la ley, en identidad referencial con la relación matrimonial, pues es esa la manera más adecuada para que tales formas de convivencia tengan una cabal protección jurídica. Y que hace a la Corte replantear el sentido y el alcance de las expresiones hombre y mujer contenidas en el artículo 42 de la Constitución. Así sostiene la decisión que:

"[L]a homosexualidad 'hace referencia a aquellas personas que experimentan una atracción erótica, preferencial o exclusiva, hacia individuos del mismo sexo biológico' y, en tal sentido, 'es un rasgo o un status de la persona que tiene que ver con la orientación y preferencia de sus deseos eróticos' [11], criterio que se ha consolidado en decisiones más recientes, en las que, por ejemplo, se ha reiterado que la diferencia de 
trato fundada en la orientación sexual de una persona se presume inconstitucional y se encuentra sometida a un control constitucional estricto o que la categoría 'orientación sexual' constituye, entonces, 'un criterio sospechoso de diferenciación' [12]”.

A los homosexuales "se les priva 'de instrumentos que les permitan desarrollarse como pareja, ámbito imprescindible para la realización personal, no solo en el aspecto sexual, sino en otras dimensiones de la vida' [cita la C-075 de 2007]. De este modo, la efectividad de la prohibición de discriminar en razón de la orientación sexual 'se aprecia en la protección de los individuos, pero no se ha manifestado en el ámbito de las parejas conformadas por personas del mismo sexo, las cuales carecen de reconocimiento jurídico' [cita la C-075 de 2007]". Es necesario poner presente de nuevo que las citas traídas de la argumentación contenida en la C-075, y ahora en la $\mathrm{C}-577$, hacen referencia a los aspectos patrimoniales analizados anteriormente en este escrito, y en los que se parte de una consideración formalmente creada y que no tuvo en cuenta las situaciones específicas que estas parejas expresan realmente en sus relaciones, con las formas que ya la ley ampara para jurídicamente recurrir en situaciones desventajosas.

Que frente a la interpretación que la Corte ha venido haciendo del artículo 42 de la Constitución, en tanto expresa que la monogamia y la heterosexualidad fundan la estructura de los vínculos familiares, esta se había venido haciendo de manera literal, encontrando plausible la argumentación de salvamentos de votos, y ahora los de las demandas, en los que se pone presente que las familias monoparentales o ensambladas son "tipos" de familia "distintos" a la formación "nuclear" que expresa el artículo 42, y, por tanto, hace necesario entender que la Constitución no podría introducir "una segregación" a otros tipos de relaciones familiares que carezcan de los elementos que acompañan las expresiones del mencionado artículo: "en la decisión libre de un hombre y una mujer de contraer matrimonio, en la voluntad libre de conformarla" (la Corte en este momento del desarrollo de su argumento solo ha traído a colación las relaciones familiares de divorciados, viudos o monoparentalismo con reproducción artificial). Así se percibe que en esta sentencia la Corte valida la consideración que hacen los salvamentos de voto, en los que se confunden las manifestaciones o vicisitudes de la vida familiar (divorciados, viudos, monoparentalismo, responsabilidad de los menores por parte de familiares o acudientes cercanos) con los elementos que dan origen a nuevos vínculos familiares (monogamia y heterosexualidad) mencionados en el artículo 42. La Corte comienza a llamar a las manifestaciones o vicisitudes de la vida familiar, "clases de familia". Categoriza, pero sin la base lógica que requeriría un elemento diferencial, pues no es lo mismo una manifestación circunstancial o una situación particular de una persona con sus familiares, que en sí un tipo de familia. Hay una taxonomía que hace de su argumento un mero artificio. La Corte primero toma el artículo en comento por lo que el mismo artículo nunca ha dicho, pero para la Corporación en esta ocasión sí que lo dice, como es el de supuestamente establecer una "clase" de familia: la nuclear, que aparentemente referiría a la monogamia y a la heterosexualidad, y que "tradicionalmente" la jurisprudencia de la Corte venía haciendo una lectura al artículo 42 de manera "literal": "el contrayente asume, con conocimiento de causa, las consecuencias que se siguen a la celebración del contrato”, una de las cuales, 
"directamente derivada del texto constitucional es la de que únicamente es admitido en Colombia el matrimonio entre un hombre y una mujer, pues la familia que se acoge por el Constituyente no es otra que la monogámica" [cita la C-659 de 1997]. "El requisito de heterosexualidad y el carácter monogámico de la unión también presiden la conceptualización de la denominada familia de hecho originada en la convivencia de los miembros de la pareja, quienes no expresan el consentimiento que es esencial en el matrimonio".

Y, entonces, se hace imperativo, bajo el supuesto de evitar una contradicción "textual" en la Constitución que dé como resultado una segregación que desproteja a alguien a causa de su orientación sexual, concluir que:

"La heterosexualidad no es, entonces, característica predicable de todo tipo de familia y tampoco lo es la consanguinidad, como lo demuestra la familia de crianza, de manera que otro ha de ser el denominador común de la institución familiar en sus diversas manifestaciones y aun cuando las causas individuales para conformar una familia son múltiples; para indagar cuál es el rasgo compartido por las distintas clases de familia y determinar si está presente en las uniones homosexuales, cabe recordar que a familias tales como la surgida del matrimonio o de la unión marital de hecho, jurídicamente se les atribuyen unos efectos patrimoniales y otros de indole personal".

La Corte mantiene en su conclusión la misma confusión: que la heterosexualidad que expresa el artículo 42 es un elemento tipificador de las familias como lo serian, por ejemplo, las circunstancias de las familias de crianza. Esta Corporación parece entender que la voluntad de hombre y mujer de conformar una familia está tan en el mismo nivel circunstancial como la situación a la que se expone un menor cuando es recibido en un hogar familiar "de crianza", descartando que el "común denominador" pueda ser la decisión o el hecho de que una pareja heterosexual decida convivir y criar. $\mathrm{Y}$ es que es cierto e inobjetable que sociológicamente a la familia no se le identifica por un solo elemento originador como podría ser la heterosexualidad de la pareja que decide convivir en matrimonio o more uxorio. Pero la perspectiva de la generalización de las manifestaciones que hay en las circunstancias personales de las personas en la relación con quienes les resultan más cercanos no es el único camino para identificar rasgos que jurídicamente permitan definir el quid de los vínculos familiares. La Corte, en la C-577, toma solo una parte de la exteriorización de los vínculos familiares sociologizándolos hasta el punto de llegar a concluir que el único común denominador entre todas las demás circunstancias antedichas en las que se puede encontrar la familia, son los vínculos afectivos con alcance solidario. Recurre de manera extrema a tomar la parte por el todo. Y, en consecuencia, llevará a que el argumento de la C-577 fuerce una equiparación formal de la solidaridad familiar con la solidaridad que da origen a los regimenes patrimoniales y asistenciales que anteriormente la misma corporación ha ideado para los integrantes de la pareja homosexual. Se cita la C-577 para ir verificando: 
"Los efectos patrimoniales y las relaciones sexuales que pueden darse o no, están determinadas por las condiciones personales de una unión que se funda y se mantiene en razón del afecto y la solidaridad de quienes le han dado origen, pues, con palabras que, aunque expuestas respecto del matrimonio, son aplicables a los compañeros y compañeras heterosexuales u homosexuales, la unión 'comporta una entrega personal' orientada 'a conformar una comunidad de vida y amor' $\mathrm{y}$, si es del caso, a 'una participación mutua en la sexualidad' (cita a la sentencia C-533 de 2000: aclaro que la cita que toma la C-577 de la C-533 no trata en nada cuestiones relativas a la homosexualidad, sino a las causales de nulidad del consentimiento matrimonial).

De conformidad con lo indicado en otros apartes de esta providencia, la sola pareja que libremente manifiesta su consentimiento o se une con vocación de permanencia es ya una familia, así en el matrimonio como en la unión marital de hecho que, tradicionalmente y para distintos efectos, ha sido aceptada como familia aún sin descendientes, luego la situación no puede ser distinta en el caso de las personas homosexuales que conforman una unión estable" (énfasis agregado).

Entonces, la Corte encuentra necesario dar un nuevo sentido literal al artículo 42 de la CP afirmando que no se ha apartado de la disposición del mismo artículo:

"La presencia en las uniones homosexuales estables del elemento que le confiere identidad a la familia más allá de su diversidad y de las variaciones que tenga su realidad, su concepto y su consecuente comprensión jurídica, las configura como familia y avala la sustitución de la interpretación que ha predominado en la Corte, debiéndose aclarar que, de conformidad con el artículo 42 superior, los vínculos que dan lugar a la constitución de la familia son naturales o jurídicos y que el cambio ahora prohijado ya no avala la comprensión según la cual el vínculo jurídico es exclusivamente el matrimonio entre heterosexuales, mientras que el vínculo natural solo se concreta en la unión marital de hecho de dos personas de distinto sexo, ya que la 'voluntad responsable de conformarla' también puede dar origen a familias surgidas de vínculos jurídicos o de vínculos naturales”.

Y se reafirma en lo anterior al amparo del concepto "constitución viviente", según el cual le permite hacer una "interpretación evolutiva" del texto del artículo 42. "Evolución" que la misma Corporación, y así lo reconoce, ha realizado ella con respecto a la protección patrimonial y asistencial ideada también por ella misma para las parejas que practican la homosexualidad. Es necesario precisar que tanto el concepto "constitución viviente" como el correspondiente a la "interpretación evolutiva" empleado en la argumentación no es idéntico al utilizado en otras sentencias en las que se examina la exequibilidad de una norma que establece una restricción a un derecho, y que por razón del cambio de unas circunstancias sociales la interpretación o el alcance del sentido de un texto deba modificarse o corregirse. Es evidente que no hay novedades con respecto a las necesidades y situaciones jurídicas que la práctica de la homosexualidad proyecta entre los mismos 
individuos y la sociedad, pues esta forma de relacionarse con los apetitos de la libido existe desde tiempos inmemoriales. Los únicos cambios sociales son los que la misma Corte ha considerado en obiter dicta, o los salvamentos de voto a sus sentencias deben hacerse, incluso para afirmar, como lo hace en la C-577, que:

"Resta apuntar que en el anterior análisis no se tuvo en cuenta el carácter monogámico de la familia que aparece como nota esencial de la única que se consideraba constitucionalmente protegida, y se omitió el examen debido a que la unión de dos personas homosexuales no cuestiona este aspecto que, por lo demás, corresponde desarrollar al legislador en razón del carácter institucional de la familia y habida cuenta de que las concepciones mayoritariamente compartidas no son favorables a la poligamia o a la poliandria que, sin embargo, podrian tener justificación en contextos culturales distintos del mayoritario y protegidos por el pluralismo y la diversidad étnica y cultural de la Nación”.

Se prepara así el terreno argumentativo para un eventual auspicio, a modo legal, de las prácticas poligámicas o plurimórficas, y quién sabe hasta cuándo, pues a pesar de que respecto a la familia homosexual la Corte sostenga que "entraña una unión singular, en cuanto se limita a dos personas y es incompatible con otras relaciones simultáneas de pareja, a más de lo cual la permanencia de la unión con estas características ha de traducirse en su notoriedad y publicidad", la impostación argumentativa y la práctica decisoria de los magistrados en esa Corte, posteriormente podría tomar esta afirmación como obsoleta en razón de unas nuevas "interpretaciones evolutivas" que los mismos $\mathrm{u}$ otros fabriquen.

Son estas, en una amplia sintesis ilustrada, las "apreciaciones globales" que para la Corte merecen el "nuevo examen". Sin embargo, es necesario volver al concepto de "apreciaciones globales". La Corte, en fallos como la C-555 de 2005, C-99 de 2006, C-542 de 2007, C-675 de 2008 y C-687 de 2011, precisamente toma este concepto para señalar que tales "apreciaciones globales" de los demandantes no ofrecen ni certeza ni pertinencia a un cargo contra una norma por examinar, equiparándolas con las mismas apreciaciones subjetivas. Pero para la decisión de la C-577 de contenido interpretativo, y que la Corte toma al examinar nuevamente la norma del artículo 113, basa su argumentación en las mentadas "apreciaciones globales”, que para esta ocasión sí dan certeza y pertinencia al examen. Y sin ofrecer al menos una explicación que precise el uso tan ambiguo del concepto "apreciaciones globales" en un nuevo fallo como la C-577, nos plantea ámbitos argumentativos formados de entresijos conceptuales creados en sus consideraciones obiter, algunos salvamentos de voto y acomodación de conceptos como los de la interpretación literal de una lectura nunca hecha, la "Constitución viviente" e "interpretación evolutiva".

130 Desde ahora, las "apreciaciones globales" no podrán entonces ser consideradas como apreciaciones subjetivas de los demandantes, y, por tanto, junto a conceptos que la misma Corte considere meramente plausibles podrán ofre- 
cerse cargos de inconstitucionalidad que factiblemente prosperen. Pues desde ya un obiter o manifestación de un magistrado disidente puede llegar a ser plausible para quienes examinen el cargo.

2. El nuevo artículo 42. En el artículo 42 de la Constitución Política, del que la intención redactora del constituyente de 1991 pretende simplemente ofrecer en la definición condiciones de igualdad para aquellas personas que responsablemente decidan fundar una familia por vía matrimonial o por vía de la convivencia more uxorio, y de la que puedan llegar a generarse vínculos con otras personas como los que provienen de la filiación y el parentesco, en donde además de la solidaridad, el amor y la estabilidad, se promuevan las exigencias racionales de la complementariedad, identidad sexual y filial; tales condiciones quedaron a merced de las interpretaciones decisorias de los integrantes de un órgano de cierre, que hasta el momento muestra carencias de rigurosos criterios de análisis para los asuntos relativos a la protección de la vida familiar.

La C-577 dejó el terreno argumentativo preparado bajo el "velo" de supuestos "precedentes jurisprudenciales" para abordar con posterioridad y con la misma praxis argumentativa la cuestión de la procreación y la crianza en la familia. A futuro, y mientras no cambie dicha praxis, no podrá ser según la familia "natural" sino la que ella considere acorde a sus "contextos", pues ella y solo ella se autodenomina la "suprema guardiana del ordenamiento jurídico".

\section{CONCLUSIÓN}

Queda así planteada la práctica de la Corte Constitucional colombiana cuando este órgano examina los supuestos contenidos en las normas jurídicas de rango legal que regulan situaciones específicas para las relaciones familiares fundadas por parejas heterosexuales, haciéndolos extensivos a las personas o parejas que practican la homosexualidad. La Corte emplea un ámbito argumentativo formalístico, creado artificiosamente por ella misma, asumiendo un protagonismo que desinstala el sistema constitucional que existe en las materias del derecho de familia y que otorga precisas competencias a los órganos legislativos, apartándose así de la intención conceptualizadora y redactora del constituyente de 1991. Aun habiendo sido reconocida por esta corporación en sus anteriores sentencias con carácter de jurisprudencia vinculante, el que la pareja que da inicio a la familia se estructura a partir de la monogamia y la heterosexualidad, la Corte Constitucional colombiana reformó el artículo 42 de la Constitución Política e impuso, por un ejercicio formalístico de sus poderes, la doctrina ideológica de que las relaciones homosexuales se deben tomar como actos que producen vínculos que caracterizan legalmente a las familias en Colombia. 


\section{BIBLIOGRAFÍA}

Albarracín Caballero, Mauricio, "Corte Constitucional y movimientos sociales: el reconocimiento judicial de los derechos de las parejas del mismo sexo en Colombia”, SUR - Revista Internacional de Derechos Humanos, 14, en http:// www.surjournal.org/esp/conteudos/getArtigo 14.php?artigo=14,artigo_01. htm. Fecha de consulta: 24 de agosto de 2012.

Ceballos Ruiz, Paola et al., "El reconocimiento de las parejas del mismo sexo: el camino hacia un concepto de familia pluralista”, Estudios Sociojurídicos (2012), en http://www.scielo.org.co. Fecha de consulta: 25 de agosto de 2012.

Corte Constitucional colombiana, Sentencias y respectivos salvamentos de voto: C-555 de 2005, C-99 de 2006; C-075, C-542 y C-81 1 de 2007; C-675 y C-798 de 2008; C-283, C-577 y C-687 de 2011, y C-238 de 2012, en http://www. corteconstitucional.gov.co. Fecha de consulta: 12 de diciembre de 2012.

Constitución Política de Colombia, en Lexbase.

Código Civil Colombiano, en Lexbase.

Cubides, Jaime Alfonso, "El rol de la jurisprudencia de la Corte Constitucional en los derechos de las parejas del mismo sexo (PMS)”, Revista Juridicas, 9-1 (2012), pp. 61-79.

Hernández P., Jackeline y ARoldo Quiroz M., "Aspectos procesales sobre los derechos de las parejas del mismo sexo”, Criterio jurídico garantista, 3 (2011), pp. 158-173.

López Moratalla, Natalia, Cerebro de mujer, cerebro de varón, Pamplona, Instituto de Ciencias para la Familia, Universidad de Navarra, 2007.

Medina Pabón, Juan Enrique, Derecho Civil: Derecho de Familia, 3 ed., Bogotá, Universidad del Rosario, 2011.

Mora Restrepo, Gabriel, Justicia constitucional y arbitrariedad de los jueces. Teoría de la legitimidad en la argumentación de las sentencias judiciales, Buenos Aires, Marcial Pons, 2009.

Mora Restrepo, Gabriel, "La deformación de la práctica jurídica contemporánea: el oficio del jurista en medio de los ideólogos”, Dikaion, 21 (2012), pp. 333-336, en http://dikaion.unisabana.edu.co/index.php/dikaion/article/ view/3212/3062. Fecha de consulta: 2 febrero de 2013.

ORdóÑEz, Stephani y VAlencia, María Cristina, "Adopción por las parejas homosexuales: de la realidad social hacia el reconocimiento judicial”, Precedente, 2 (2013), pp. 227-228.

PÁez Ramírez, Manuel, "La sentencia C-577 de 2011 y el matrimonio igualitario en Colombia”, Revista Derecho del Estado (2013), en http://www.scielo.org.co/ scielo.php. Fecha de consulta: 25 de agosto de 2013. 
Procuraduría General de la Nación, Conceptos 4876 del 6 de julio de 2010 y 5110 del 1 de marzo de 2011.

Pulido Ortiz, Fabio Enrique y Burgos, Jenny Carolina, "Valor epistémico de la democracia y jurisprudencia de la Corte Constitucional colombiana”, Estudios de Derecho y Gobierno, 2-2 (2010), en http://portalweb.ucatolica.edu.co/easyWeb2/files/54_10647_valor-epistemico-democracia-.pdf. Fecha de consulta: 3 de septiembre de 2012.

Universidad Austral, Informe: Matrimonio homosexual y adopción por parejas del mismo sexo (2010), Buenos Aires, en http://www.aica.org/aica/documentos_files/Otros_Documentos/Varios/MATRIMONIO_HOMOSEXUAL_Y_ADOPCION_Univ.Austral.pdf. Fecha de consulta: 25 de agosto de 2012. 
